\title{
Growth Forecast Errors and Fiscal Multipliers
}

\author{
Olivier Blanchard and Daniel Leigh
}




\title{
IMF Working Paper
}

\author{
Research Department
}

\section{Growth Forecast Errors and Fiscal Multipliers}

Prepared by Olivier Blanchard and Daniel Leigh

Authorized for distribution by Olivier Blanchard

January 2013

\begin{abstract}

\section{This Working Paper should not be reported as representing the views of the IMF.}

The views expressed in this Working Paper are those of the author(s) and do not necessarily represent those of the IMF or IMF policy. Working Papers describe research in progress by the author(s) and are published to elicit comments and to further debate.

This paper investigates the relation between growth forecast errors and planned fiscal consolidation during the crisis. We find that, in advanced economies, stronger planned fiscal consolidation has been associated with lower growth than expected, with the relation being particularly strong, both statistically and economically, early in the crisis. A natural interpretation is that fiscal multipliers were substantially higher than implicitly assumed by forecasters. The weaker relation in more recent years may reflect in part learning by forecasters and in part smaller multipliers than in the early years of the crisis.
\end{abstract}

JEL Classification Numbers: E32, E62, H20, H5, H68

Keywords: Fiscal policy, forecasting, taxation, government expenditure, output fluctuations

Author’s E-Mail Address: oblanchard@imf.org; dleigh@imf.org 


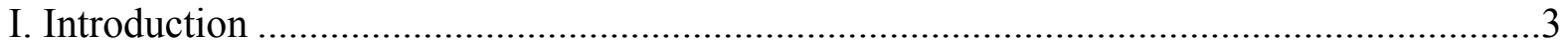

II. Forecast Errors and Fiscal Consolidation Forecasts ..................................................6

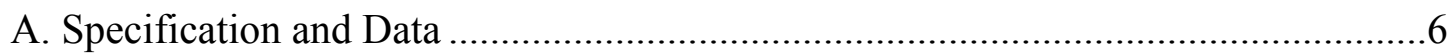

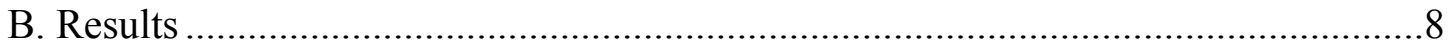

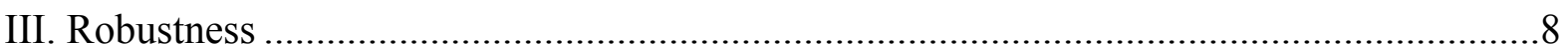

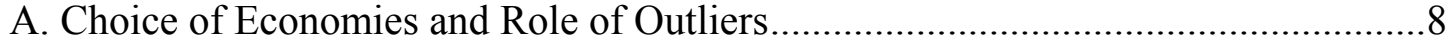

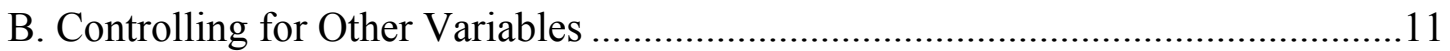

Actual vs. Planned Fiscal Consolidation ..................................................... 13

C. Different Forecast Vintages ...................................................................... 14

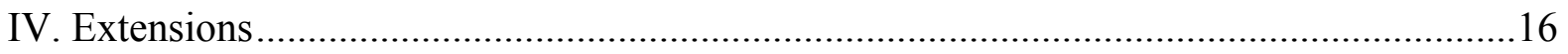

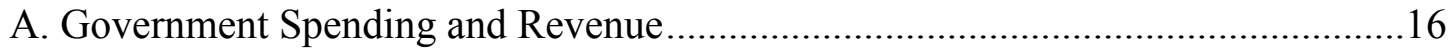

B. Components of Aggregate Spending and Unemployment .................................17

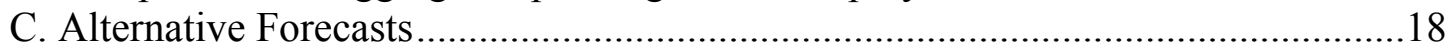

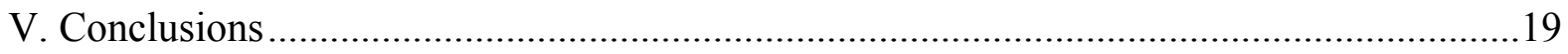

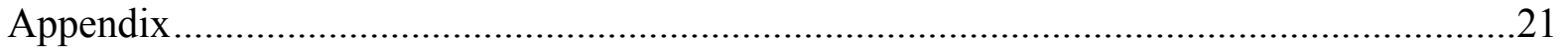

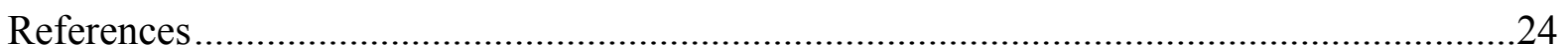




\section{INTRODUCTION ${ }^{1}$}

With many economies in fiscal consolidation mode, there has been an intense debate about the size of fiscal multipliers. At the same time, activity has disappointed in a number of economies undertaking fiscal consolidation. A natural question therefore is whether forecasters have underestimated fiscal multipliers, that is, the short-term effects of government spending cuts or tax hikes on economic activity.

In a box published in the October 2012 World Economic Outlook (WEO; IMF, 2012b), we focused on this issue by regressing the forecast error for real GDP growth on forecasts of fiscal consolidation. Under rational expectations, and assuming that forecasters used the correct model for forecasting, the coefficient on the fiscal consolidation forecast should be zero. If, on the other hand, forecasters underestimated fiscal multipliers, there should be a negative relation between fiscal consolidation forecasts and subsequent growth forecast errors. In other words, in the latter case, growth disappointments should be larger in economies that planned greater fiscal cutbacks. This is what we found.

In the box published in October, we focused primarily on forecasts made for European economies in early 2010. The reason was simple: A number of large multiyear fiscal consolidation plans were announced then, particularly in Europe, and conditions for largerthan-normal multipliers were ripe.

First, because of the binding zero lower bound on nominal interest rates, central banks could not cut interest rates to offset the negative short-term effects of a fiscal consolidation on economic activity. Christiano, Eichenbaum, and Rebelo (2011) have shown, using a dynamic stochastic general equilibrium (DSGE) model, that under such conditions, fiscal multipliers can exceed 3. ${ }^{2}$ Since episodes characterized by a binding zero lower bound (also referred to as "liquidity trap" episodes) have been rare, only a few empirical studies investigate fiscal multipliers under such conditions. Based on data for 27 economies during the $1930 \mathrm{~s}-\mathrm{a}$

\footnotetext{
${ }^{1}$ We are grateful to Laurence Ball, John Bluedorn, Marcos Chamon, Petya Koeva Brooks, Oli Coibion, Jörg Decressin, Kevin Fletcher, Philip Lane, David Romer, Sven Jari Stehn, and numerous IMF seminar participants for helpful comments, to Eric Bang, Shan Chen, Angela Espiritu, Chanpheng Fizzarotti, and Daniel Rivera for excellent research assistance, and to Linda Kean and Cristina Quintos for superb editorial support. The data and estimation codes for the analysis can be found at http://www.imf.org/external/pubs/ft/wp/2013/Data/wp1301.zip

${ }^{2}$ Other papers that use a theoretical model to analyze the effects of fiscal policy also conclude that fiscal multipliers rise significantly at the zero lower bound. Hall (2009) finds that, in an economy with an output multiplier below 1 in normal times, the multiplier can rise to 1.7 when the zero lower bound binds. See also Coenen and others (2010), IMF (2010a), and Woodford (2011). It is worth acknowledging, however, that even at the zero lower bound, central banks have used quantitative and qualitative easing measures, which can lower interest rates at longer maturities.
} 
period during which interest rates were at or near the zero lower bound-Almunia and others (2010) have concluded that fiscal multipliers were about $1.6 .^{3}$

Second, lower output and lower income, together with a poorly functioning financial system, imply that consumption may have depended more on current than on future income, and that investment may have depended more on current than on future profits, with both effects leading to larger multipliers (Eggertsson and Krugman, 2012). ${ }^{4}$

Third, and consistent with some of the above mechanisms, a number of empirical studies have found that fiscal multipliers are likely to be larger when there is a great deal of slack in the economy. Based on U.S. data, Auerbach and Gorodnichenko (2012b) have found that fiscal multipliers associated with government spending can fluctuate from being near zero in normal times to about 2.5 during recessions. ${ }^{5}$ If fiscal multipliers were larger than normal and growth projections implicitly assumed multipliers more consistent with normal times, then growth forecast errors should be systematically correlated with fiscal consolidation forecasts.

Our October 2012 box generated many comments, criticisms, and suggestions. In this paper, we restate our methodology, revisit our results, examine their robustness, and consider a number of extensions.

Section II presents our estimation approach and reports our baseline results. Our forecast data come from the spring 2010 IMF World Economic Outlook (IMF, 2010c), which includes forecasts of growth and fiscal consolidation-measured by the change in the structural fiscal balance - for 26 European economies. We find that a 1 percentage point of GDP rise in the fiscal consolidation forecast for 2010-11 was associated with a real GDP loss during 2010-11 of about 1 percent, relative to forecast. Figure 1 illustrates this result using a scatter plot. A natural interpretation of this finding is that multipliers implicit in the forecasts were, on average, too low by about 1 .

In Section III, we investigate the robustness of the baseline result along three dimensions.

First, we consider the sensitivity of the baseline results to outliers and to the choice of economies in the sample. Robustness checks indicate an unexpected output loss, relative to

\footnotetext{
${ }^{3}$ See also Eichengreen and O'Rourke (2012).

${ }^{4}$ Eggertsson and Krugman (2012) show, using a New Keynesian-style model, that when some households with an overhang of debt are forced into rapid deleveraging, their spending depends on current income rather than on expected future income, and that under these conditions, fiscal multipliers rise well above 1.

${ }^{5}$ Studies based on data for other advanced economies that confirm the result of larger multipliers during economic downturns include Auerbach and Gorodnichenko (2012b); Baum, Poplawski-Ribeiro, and Weber (2012); Batini, Callegari, and Melina (2012); and IMF (2012b).
} 
forecast, that is for the most part near 1 percent and typically above 0.7 percent, for each 1 percent of GDP fiscal consolidation. We obtain similar results when we extend the analysis to forecasts for all advanced economies. However, and not surprisingly given their different economic circumstances, we find no evidence of multipliers being over- or under-estimated for emerging market economies during that period.

Second, we reestimate our baseline specification while adding control variables, ranging from initial fiscal and current account balances to initial bank credit risk and household debt levels. These could plausibly have both affected the growth forecast error and been correlated with fiscal consolidation forecasts. Not controlling for such factors could influence the estimated relation between fiscal consolidation forecasts and growth forecast errors. We find, however, that our results are robust to the introduction of such controls.

Third, we look at the results for other time intervals since the start of the crisis, as well as the results for "normal times" (1997-2008). Looking within the crisis, we find evidence of more underestimation of fiscal multipliers earlier in the crisis (for the time intervals 2009-10 and 2010-11) than later in the crisis (2011-12 and 2012-13). Results for the earlier samples yield coefficients typically between 0.7 and 1.0. Results for the later samples yield coefficients typically between 0.3 and 0.5 and are less statistically significant. Interestingly, and again perhaps not surprisingly, we find no evidence of systematic forecast errors related to planned changes in fiscal policy during the precrisis decade (1997-2008).

Having discussed robustness, Section IV turns to three extensions of our baseline results.

First, we check whether the baseline results differ depending on whether the fiscal consolidation reflects changes in government spending or changes in revenue. The results suggest that fiscal multipliers were, on average, underestimated for both sides of the fiscal balance, with a slightly larger degree of underestimation associated with changes in government spending.

Second, we examine forecast errors for the unemployment rate and for the components of GDP. We find that forecasters significantly underestimated the increase in unemployment and the decline in private consumption and investment associated with fiscal consolidation.

Finally, we compare the baseline results obtained using IMF forecast errors with those obtained using the forecast errors of other forecasters, including the European Commission (EC), the Organization for Economic Cooperation and Development (OECD), and the Economist Intelligence Unit (EIU). Here, we find that the results hold for all the forecasters considered, with coefficients ranging from -1.1 to -0.4 . The results are strongest, in terms of both economic and statistical significance, for forecasts published by the IMF and, to a slightly lesser extent, by the EC. 
We conclude in Section $\mathrm{V}$ with a discussion of what our results do and do not imply for actual multipliers. We conclude that multipliers were substantially above 1 in the early years of the crisis. The lower coefficients in recent years may reflect in part learning by forecasters and in part smaller actual multipliers than in the early years of the crisis. We end with a number of caveats.

First, forecasters do not typically use explicit multipliers, but instead use models in which the actual multipliers depend on the type of fiscal adjustment and on other economic conditions. Thus, we can only guess what the assumed multipliers, and by implication the actual multipliers, have been during the crisis.

Second, our results only give average multipliers for groups of countries, and individual countries may well have larger or smaller multipliers than the average.

Third, our findings that short-term fiscal multipliers have been larger than expected do not have mechanical implications for the conduct of fiscal policy. Some commentators interpreted our earlier box as implying that fiscal consolidation should be avoided altogether. This does not follow from our analysis. The short-term effects of fiscal policy on economic activity are only one of the many factors that need to be considered in determining the appropriate pace of fiscal consolidation for any single economy.

\section{Forecast ERrors AND Fiscal Consolidation Forecasts}

In this section, we explain our estimation approach, describe the dataset, and report our baseline results.

\section{A. Specification and Data}

To investigate whether growth forecast errors have been systematically related to fiscal consolidation forecasts, our approach is simple: we regress the forecast error for real GDP growth in years $t$ and $t+1$ on forecasts of fiscal consolidation for $t$ and $t+1$ made early in year $t$. We focus on two-year intervals to allow for lagged effects of fiscal policy. Under rational expectations, and assuming that the correct model has been used for forecasting, the coefficient on the forecast of fiscal consolidation should be zero. The equation estimated is therefore:

$$
\text { Forecast Error of } \Delta Y_{i, t: t+1}=\alpha+\beta \text { Forecast of } \Delta F_{i, t: t+1 \mid t}+\varepsilon_{i, t: t+1} \text {, }
$$

where $\Delta Y_{i, t: t+1}$ denotes cumulative (year-over-year) growth of real GDP $(Y)$ in economy $i-$ that is, $\left(Y_{i, t+1} / Y_{i, t-1}-1\right)$ - and the associated forecast error is $\Delta Y_{i, t: t+1}-\mathrm{f}\left\{\Delta Y_{i, t: t+1} \mid \Omega_{t}\right\}$, where f denotes the forecast conditional on $\Omega_{t}$, the information set available early in year $t . \Delta F_{i, t: t+1}$ denotes the change in the general government structural fiscal balance in percent of potential 
GDP, a widely used measure of the discretionary change in fiscal policy for which we have forecasts. ${ }^{6}$ Positive values of $\Delta F_{i, t: t+1}$ indicate fiscal consolidation, while negative values indicate discretionary fiscal stimulus. The associated forecast is "Forecast of $\Delta F_{i, t: t+1 \mid t}$ " defined as $\mathrm{f}\left\{F_{t+1, i}-F_{t-1, i} \mid \Omega_{t}\right\}$. Under the null hypothesis that fiscal multipliers used for forecasting were accurate, the coefficient, $\beta$, should be zero. ${ }^{7}$ Our data come from the IMF's WEO database. We have posted the underlying data and estimation codes required to replicate all the results reported in this paper on the IMF's website. ${ }^{8}$

As explained above, we focus in our baseline on forecasts made for European economies in early 2010. Growth forecast errors thus measure the difference between actual cumulative real GDP (year-over-year) growth during 2010-11, based on the latest data, minus the forecast prepared for the April $2010 \mathrm{WEO}$ (IMF, 2010c). ${ }^{9}$ The forecast of fiscal consolidation is the forecast of the change in the structural fiscal balance as a percent of potential GDP during 2010-11, as prepared for the April 2010 WEO. We use all available data for the European Union's (EU's) 27 member states, as well as for the remaining three European economies classified as "advanced" in the WEO database: Iceland, Norway, and Switzerland. WEO forecasts of the structural fiscal balance made in April 2010 are unavailable for Estonia, Latvia, Lithuania, and Luxembourg. Thus, based on data availability, our baseline sample consists of 26 economies $(27+3-4) .{ }^{10}$ As we report below, filling the four missing

${ }^{6}$ As the WEO data appendix explains,

\begin{abstract}
"The structural budget balance refers to the general government cyclically adjusted balance adjusted for nonstructural elements beyond the economic cycle. These include temporary financial sector and asset price movements as well as one-off, or temporary, revenue or expenditure items. The cyclically adjusted balance is the fiscal balance adjusted for the effects of the economic cycle; see, for example, A. Fedelino. A. Ivanova and M. Horton 'Computing Cyclically Adjusted Balances and Automatic Stabilizers' IMF Technical Guidance Note No. 5, http://www.imf.org/external/pubs/ft/tnm/2009/tnm0905.pdf."
\end{abstract}

We express the structural balance as a ratio to potential GDP, but results based on the structural balance expressed as a ratio to nominal GDP are very similar, as we report below.

${ }^{7}$ Estimates of equation (1) thus provide a simple test of forecast efficiency. Under the null of forecast efficiency, information known when the forecasts were made should be uncorrelated with subsequent forecast errors. A finding that the coefficient $\beta$ is negative would indicate that forecasters tended to be optimistic regarding the level of growth associated with fiscal consolidation.

${ }^{8}$ The data can be found at http://www.imf.org/external/pubs/ft/wp/2013/Data/wp1301.zip. We have posted the underlying dataset in Excel and STATA, along with the STATA codes that produce all the empirical results, and a "Readme" file with replication instructions. One series used in Table 6 of the appendix, namely the IMF vulnerability rating, is confidential information and could not be included in the data file.

${ }^{9}$ Throughout this paper, forecast errors are computed relative the latest (October 2012 WEO) database.

${ }^{10}$ The 26 economies are Austria, Belgium, Bulgaria, Cyprus, Czech Republic, Germany, Denmark, Finland, France, Greece, Hungary, Ireland, Iceland, Italy, Malta, Netherlands, Norway, Poland, Portugal, Romania, Slovak Republic, Slovenia, Spain, Sweden, Switzerland, and the United Kingdom. 
observations with forecasts from the spring 2010 EC European Economic Forecast (EC, 2010) makes little difference to the results.

\section{B. Results}

Table 1 reports our baseline estimation results. We find a significant negative relation between fiscal consolidation forecasts made in 2010 and subsequent growth forecast errors. In the baseline specification, the estimate of $\beta$, the coefficient on the forecast of fiscal consolidation, is -1.095 ( $t$-statistic $=-4.294)$, implying that, for every additional percentage point of GDP of fiscal consolidation, GDP was about 1 percent lower than forecast. ${ }^{11}$ Figure 1 illustrates this result using a scatter plot. The coefficient is statistically significant at the 1 percent level, and the $R^{2}$ is 0.496 . The estimate of the constant term, $0.775(t$-statistic $=$ 2.023 ) has no strong economic interpretation. ${ }^{12}$

\section{ROBUSTNESS}

The results reported above suggest that economies with larger planned fiscal consolidations tended to have larger subsequent growth disappointments. In this section, we examine the robustness of this result along three main dimensions. First, we repeat the analysis for different groups of economies and examine the role of potentially influential outlier observations. Second, we reestimate the baseline equation (1) while adding control variables that could plausibly have both affected the growth forecast error and been correlated with fiscal consolidation forecasts. Not controlling for such factors could influence the estimated relation between fiscal consolidation forecasts and growth forecast errors. Finally, we consider how the results change for forecasts made in more normal times (1997-2008) and for other time intervals since the start of the crisis (2009-12).

\section{A. Choice of Economies and Role of Outliers}

First, we investigate the sensitivity of the baseline results to changes in the economies included in the sample. We start by seeing how the results change when we replace the

\footnotetext{
${ }^{11}$ In an earlier version of this paper, which considered results for a sample of EU and major advanced economies, the results were similar: the slope coefficient estimate was -1.164 , and the $R$-squared was 0.506 . Throughout the paper, we report statistical inference based on heteroskedasticity-robust standard errors.

${ }^{12}$ The constant term, 0.775 , equals the sample mean of the growth forecast error, 0.193 percentage point, minus the slope coefficient $(\beta),-1.095$, times the sample mean of fiscal consolidation, 0.532 percentage point. Thus, $0.775=0.193-(-1.095 \times 0.532)$. If we express the structural fiscal balance in percent of headline (rather than potential) GDP and rerun the baseline regression in that form, we obtain a very similar estimate of $\beta(-1.077$, with a $t$-statistic of -3.900 ).
} 
missing WEO forecasts for four EU member states-Estonia, Latvia, Lithuania, and Luxembourg - with EC forecasts. As Table 1 reports, this makes little difference to the results. Next, we consider how the results change when we remove observations associated with the largest fiscal policy changes. While such policy changes are worth considering, it is natural to ask how important they are for the results. As Table 1 reports, when we remove the two largest policy changes (those for Germany and Greece), the estimate of $\beta$ declines to $0.776(t$-statistic $=-2.249)$ but remains statistically significant at the 5 percent level. Thus, concerns raised by some in reaction to an earlier version of this paper, that excluding the largest policy changes from the sample might render the results insignificant, seem exaggerated. ${ }^{13}$

We also investigate whether forecasts made for economies with IMF programs are driving the baseline results. As Table 1 reports, excluding from the sample the five economies that had IMF programs in 2010 or 2011 - Greece, Iceland, Ireland, Portugal, and Romaniayields an estimate of $\beta$ of -0.812 ( $t$-statistic $=-2.890)$, which is statistically significant at the 1 percent level and is not statistically distinguishable from our baseline estimate of -1.095 . Similarly, excluding the four economies classified as "emerging" in the WEO database from the sample (Bulgaria, Hungary, Poland, and Romania) has little effect on the point estimate of $\beta$, which is $-0.992(t$-statistic $=-3.568)$ in this case. ${ }^{14}$

Second, we investigate more formally the sensitivity of the results to outliers by applying three accepted estimation strategies designed to resist the influence of potential outliers. In particular, we reestimate the baseline specification using robust regression, which downweights observations with larger absolute residuals using iterative weighted least squares (Andersen, 2008). ${ }^{15}$ Since robust regression is more resistant to outliers than is ordinary least squares (OLS), this provides a check of whether outliers are unduly influencing the baseline OLS results. As Table 1 reports, the robust regression estimate of $\beta$ is -1.279 ( $t$-statistic $=-$ 6.989), which is similar to the baseline OLS estimate and statistically significant at the 1

\footnotetext{
${ }^{13}$ Financial Times, October 12, 2012.

${ }^{14}$ As a further robustness check, we examine whether the coefficient $\beta$ was significantly different for European economies in the euro area or with a peg to the euro. We reestimate equation (1) while allowing coefficients $\beta$ and $\alpha$ to be different for the nine economies in the sample that are not euro area members and do not have peg to the euro (Czech Republic, Hungary, Iceland, Norway, Poland, Romania, Sweden, Switzerland, and the United Kingdom), using dummy variables. We fail to reject the null that the coefficient $\beta$ was the same for both groups. The estimate of $\beta$ for the euro area or euro peg economies is $-0.982(t$-statistic $=-3.198)$, and the $p$ value for the null hypothesis that $\beta$ was the same for the remaining economies is 0.335 .

${ }^{15}$ The robust regression procedure is implemented in STATA via the rreg command. As Hamilton (2012) explains, the procedure starts by estimating the equation via OLS. Next, it drops observation with Cook's distance greater than 1. Finally, an iterative process occurs, during which weights are calculated based on absolute residuals until the maximum change between the weights between successive iterations is below tolerance. Overall, the procedure down-weights influential outliers.
} 
percent level. Next, we apply a quantile regression approach, which minimizes the sum of the absolute residuals about the median, rather than the sum of the squares of the residuals about the mean as in OLS, making the estimates less affected by outliers. ${ }^{16}$ The quantile regression estimate of $\beta$ is -1.088 ( $t$-statistic $=-4.533$ ) and is statistically significant at the 1 percent level. Finally, we also investigate the role of outliers using Cook's distance method, by discarding observations with Cook's distance greater than $4 / N$, where $N$ is the sample size, and obtain a $\beta$ estimate of -0.921 ( $t$-statistic $=-4.244)$ that is, again, statistically significant at the 1 percent level. Overall, these three methods that resist the pull of outliers confirm the baseline OLS result of a negative relation between fiscal consolidation forecasts and growth forecast errors.

Third, we consider how the results change when we broaden the sample to include the entire group of economies classified as "advanced" in the WEO database. This wider group adds 10 economies to our baseline sample. ${ }^{17}$ For most of these additional economies, including Australia, Hong Kong SAR, Israel, Korea, New Zealand, Singapore, and Taiwan Province of China, the conditions for larger-than-normal multipliers discussed above, such as the liquidity trap, are less relevant, which leads us to expect a smaller absolute value of $\beta$ for this sample. As Table 1 reports, the estimate of $\beta$ declines to $-0.538(t$-statistic $=-1.322)$ for this group of economies and is no longer statistically significant. By contrast, when we narrow this broad sample to include only economies that were, arguably, in a liquidity trap during this period, the estimate of $\beta$ rises in absolute value to $-0.986(t$-statistic $=-3.652) .{ }^{18}$

The reduced statistical significance of the OLS estimates for this broader sample is, however, primarily driven by influential outliers, as Table 1 reports. The robust regression, which down-weights influential outliers, yields an estimate of $\beta$ of $-0.955(t$-statistic $=-4.751)$, which is close to the baseline sample estimate and is statistically significant at the 1 percent level. The stark difference between these robust regression results and the OLS results highlights the fact that the OLS results are heavily influenced by outliers in this broader sample. The procedure gives the two smallest weights to New Zealand and Singapore due to their large absolute residuals. ${ }^{19}$ Similarly, the quantile regression yields an estimate of $\beta$ of -

\footnotetext{
16 The quantile regression approach is implemented via the qreg command in STATA.

${ }^{17}$ The 10 additional economies are Australia, Canada, Korea, Hong Kong SAR, Israel, Japan, New Zealand, Singapore, Taiwan Province of China, and the United States.

${ }^{18}$ For the purposes of this exercise, we define the set of economies in a liquidity trap as those for which the central bank's main nominal policy interest rate reached 1 percent or less during 2010-11. This excludes the following economies from the sample: Australia, Hong Kong SAR, Hungary, Iceland, Israel, Korea, New Zealand, Norway, Poland, Romania, Singapore, Sweden, and Taiwan Province of China.

${ }^{19}$ The residual for Singapore is 10.475 percentage points, while that of New Zealand is -6.832 percentage points. The large negative residual for New Zealand reflects the 2010 earthquake, which had major implications for growth and occurred after the publication of the WEO forecast (which, in turn, already assumed some fiscal stimulus planned prior to the earthquake). The reason for Singapore's large positive residual is less clear,
}

(continued...) 
$0.999(t$-statistic $=-7.866)$, and the estimate based on excluding observations with Cook's distance greater than $N / 4$ yields an estimate of $-0.746(t$-statistic $=-2.674)$. Overall, once we adjust for the influence of outliers, the results for the broader group of all advanced economies are consistent with those obtained for the baseline European sample. Finally, we repeat the analysis for the group of 14 (non-European) emerging market economies for which WEO forecasts of the structural fiscal balance made in early 2010 are available. ${ }^{20}$ As Table 1 reports, our results provide no evidence that forecasters underestimated fiscal multipliers for this group of economies. The estimate of $\beta$ is 0.007 ( $t$ statistic $=0.016$ ). Moreover, in this case, the lack of statistical significance is not merely driven by influential outliers - reestimating the relation for emerging market economies using the robust regression, the quantile regression, and excluding Cook's distance outliers leads to the same conclusion. These results, admittedly based on a very small sample, are consistent with the notion that the conditions leading to larger-than-normal fiscal multipliers discussed above are currently less relevant for these economies. ${ }^{21}$

\section{B. Controlling for Other Variables}

Having established that the baseline results are not unduly influenced by outliers, we check if the results are robust to controlling for additional variables that could plausibly have triggered both planned fiscal consolidation and lower-than-expected growth. The omission of such variables could bias the analysis toward finding that fiscal multipliers were larger than assumed.

In the context of forecast evaluation, controlling for other variables that were in the information set of forecasters is warranted. The question is: based on the information they had available at the time forecasts were made, did forecasters underestimate the effect of fiscal consolidation on growth, or did they instead underestimate the effect of other variables on growth? It is worth emphasizing that, to answer this question, controlling for ex-post developments - those unknown at the time forecast were made - is not valid. For example, an ex-post rise in sovereign borrowing costs could be the result of lower-than-expected growth as well as the cause of lower growth (Cottarelli and Jaramillo, 2012; Romer, 2012). In this case, lower-than-expected growth caused by fiscal consolidation could trigger a rise in sovereign borrowing costs, and these higher borrowing costs could, in turn, further reduce

although it was associated with a growth spike of 45.9 percent (quarter-over-quarter, annualized) in 2010:Q1 (IMF, 2010b, p. 41).

${ }^{20}$ These emerging market economies are Argentina, Brazil, Chile, China, India, Indonesia, Malaysia, Mexico, Russia, South Africa, Swaziland, Thailand, Turkey, and Ukraine.

${ }^{21}$ We revisit the case of emerging market economies based on a larger sample spanning more years in section IIIC, again finding little evidence of fiscal multipliers being underestimated for this group. 
growth. Even if controlling for such variables significantly changed the estimate of $\beta$, the coefficient would no longer have an economic interpretation. ${ }^{22}$

Relatedly, controlling for the forecast error of the change in fiscal policy does not, in our application, provide a way of estimating the causal effect of fiscal policy on growth. Over the two-year intervals that we consider, changes in fiscal policy are unlikely to be orthogonal to economic developments. Thus, the forecast error of fiscal consolidation over our two-year intervals cannot be interpreted as an identified fiscal shock and cannot yield estimates of actual fiscal multipliers. A large literature seeks to identify such exogenous shifts in government spending and revenues. Doing so has proven difficult and lies beyond the scope of our analysis.

We start by considering the role of sovereign debt problems. Are the baseline results picking up greater-than-expected effects of sovereign debt problems rather than the effects of fiscal consolidation? As Table 2 reports, the results are robust to controlling for the initial (end2009) government-debt-to-GDP ratio, for the initial fiscal-balance-to-GDP ratio, and for the initial structural fiscal-balance-to-GDP ratio. To ensure that these variables were indeed in the forecasters' information set, the source of the data is the same (from the April 2010 WEO-IMF, 2010c) as for the fiscal consolidation forecasts. However, since these (backward-looking) measures of the fiscal accounts do not necessarily fully capture perceived future sovereign debt problems, we also control for perceived sovereign default risk, as measured by the sovereign credit default swap (CDS) spread in the first quarter of $2010 .{ }^{23}$ The estimate of $\beta$ is, again, largely unchanged.

Next, we check if the baseline result is picking up greater-than-expected effects of financial sector stress rather than the unexpected effects of fiscal consolidation. As Table 2 reports, the relation holds when we control for the initial bank CDS spread. ${ }^{24}$ We obtain similar results when controlling for the occurrence of banking crises, based on a zero-one event dummy

\footnotetext{
${ }^{22}$ Some comments on an earlier version of this analysis discussed the role of such ex-post developments. For completeness, we report results while controlling for ex-post developments in Appendix Table 1, finding that they do not materially influence the estimate of $\beta$.

${ }^{23}$ Data for the sovereign CDS spreads come from Bloomberg LP. We use the average five-year CDS spread in 2010:Q1, which is arguably a good proxy for the information about CDS spreads available to forecasters during the preparation of the April 2010 WEO forecasts. The results are similar if we use the level of the sovereign CDS spread in 2009:Q4.

${ }^{24}$ Data for the bank CDS spreads come from Bloomberg LP. We use the average five-year bank CDS spread in 2010:Q1. For each economy, the bank CDS spread is the bank-asset-weighted average. For our baseline European sample, bank CDS spreads are available for 15 economies-Austria, Belgium, Denmark, France, Germany, Greece, Ireland, Italy, Netherlands, Norway, Portugal, Spain, Sweden, Switzerland, and the United Kingdom. For the remaining 11 economies, we fill the missing observations using the predicted values of the bank CDS spread from a regression of bank CDS spreads on sovereign CDS spreads during 2009-10 - a strong relation with a slope coefficient of $1.093(t$-statistic $=11.52)$.
} 
variable indicating a systemic banking crisis, as identified by Laeven and Valencia (2012). Finally, it is worth recalling that, as reported in Table 1, the baseline result is robust to excluding economies with severe financial stress-namely, those with IMF programs.

The baseline finding also holds up to controlling for the fiscal consolidation of trading partners. To the extent that fiscal consolidations were synchronized, fiscal consolidation by others may be driving the results. In particular, forecasters may have understated the crosscountry spillover effects of fiscal policy, which, as recent research indicates, can be large (Auerbach and Gorodnichenko, 2012c). However, when we control for trade-weighted fiscal consolidation of other countries (scaled by the share of exports in GDP), the results are virtually unchanged. ${ }^{25}$

To investigate the role of precrisis external imbalances that may have triggered both fiscal consolidation and larger-than-expected headwinds to growth, we control for the precrisis (2007) current-account-deficit-to-GDP ratio, again taken from the April 2010 WEO database (IMF, 2010c), and find similar results. We obtain similar results when controlling for the stock of precrisis (2007) net foreign liabilities in percent of GDP, based on the updated and extended version of dataset constructed by Lane and Milesi-Ferretti (2007).

Finally, we investigate the possible role of household debt overhang, which can have negative effects on economic activity (Mian, Rao, and Sufi, 2011; IMF, 2012c, and others). In particular, we reestimate the baseline equation while controlling for the precrisis (2007) level of the household debt-to-disposable-income ratio. As Table 2 reports, controlling for this variable does not materially influence the estimate of $\beta .^{26}$

\section{Actual versus Planned Fiscal Consolidation}

We address next the possibility that, although the assumed multipliers were correct, countries with more ambitious consolidation programs may have implemented more fiscal consolidation than originally planned. The concern, here, is that the baseline result reflects

\footnotetext{
${ }^{25}$ The estimate of the coefficient on partner-country fiscal consolidation, -0.548 , while not statistically significant, is fairly large. It implies that a joint 1 percent of GDP fiscal consolidation by the domestic economy and by its partners (weighted by the share of exports in GDP) would lead to a domestic output loss of 1.652 percent, relative to forecast $(-0.548$ plus the estimate of $\beta$ in this specification, -1.105$)$. However, since the estimate of the coefficient on partner-country fiscal consolidation is highly imprecise (the standard error is 1.343), this result needs to be interpreted cautiously.

${ }^{26}$ Based on U.S. data, Mian, Rao, and Sufi (2011) show that a higher level of the household debt-to-income ratio in 2007 is associated with sharper declines in U.S. economic activity during the crisis. Our measure of household debt is the household sector's total financial liabilities in percent of household disposable income, which we take from the dataset compiled for the April 2012 WEO chapter on household debt (IMF, 2012c). The baseline results also hold up to additional robustness checks, including controlling for the initial forecast for 2010-11 real growth, both in terms of GDP and in terms of terms of potential GDP.
} 
the fact that actual fiscal consolidation was much larger than planned rather than actual multipliers being larger than expected. It is worth emphasizing that this issue would only lead to a biased estimate of $\beta$ to the extent that the unexpected fiscal consolidation (the fiscal consolidation forecast error) was correlated with the initial fiscal consolidation forecast.

We investigate this possibility using a two-stage-least-squares approach: the first stage involves a regression of actual fiscal consolidation on the forecast of fiscal consolidation; and the second stage is a regression of the growth forecast error on the instrumented values of actual fiscal consolidation obtained in the first stage. As Table 3 reports, the first stage is strong, and the slope coefficient is $1.057(t$-statistic $=5.714)$. This coefficient close to 1 indicates that, on average, actual consolidation was neither smaller nor larger than expected. ${ }^{27}$ The second stage indicates that a 1 percent of GDP fiscal consolidation is associated with a1.036 percentage point output forecast error $(t$-statistic $=-4.518)$, which is, again, close to the baseline.

Overall, these robustness checks suggest that the results for the baseline sample are robust to the inclusion of additional variables that could potentially bias the results toward finding that actual multipliers were larger than assumed multipliers. In particular, controlling for variables that measure other weaknesses of the economy that might be associated with fiscal consolidation do not materially affect the coefficient on the forecast of fiscal consolidation. ${ }^{28}$

\section{Different Forecast Vintages}

So far, our analysis has focused on forecasts made in early 2010, when a number of large fiscal consolidation plans were announced. But it is worth examining whether the relation also holds for forecasts made in other years. We start by examining forecasts made in all years since the start of the crisis (2009-12), both jointly and individually. This exercise has the advantage of raising the sample size to 105 observations, up from the 26 observations in our baseline sample. Then, we consider forecasts made in more normal times - the precrisis decade (1997-2008). For this precrisis sample, our expectation is that in these more normal times, the coefficient $\beta$ should be close to zero.

\footnotetext{
${ }^{27}$ The constant term is $0.907(t$-statistic $=2.834)$, as reported in Table 3 , which indicates that economies did, on average, tend to consolidate more than initially planned. However, the key result for our application is that the forecast error of fiscal consolidation is not correlated with the initial fiscal consolidation forecast, as the slope coefficient of 1.057 indicates. Equivalently, regressing the forecast error of fiscal consolidation on the initial forecast yields a near-zero coefficient ( 0.057 with a $t$-statistic of 0.190$)$.

${ }^{28}$ Not surprisingly, repeating this analysis for the broader group of all advanced economies produces results similar to those reported in Table 1, as reported in Appendix Table 2. In particular, based on OLS, which is strongly influenced by outliers in this sample, as discussed above, the estimate of $\beta$ is negative but statistically insignificant for each case of adding an additional control variable. But using the robust regression approach, the estimate of $\beta$ is statistically significant in each case, and ranges from -0.729 to -0.973 .
} 
First, we discuss the results obtained when considering the set of two-year intervals since the start of the crisis (2009-12) together in a panel. The equation estimated is similar to equation (1), except that it now includes a vector of time-fixed effects, $\lambda_{t}$ :

$$
\text { Forecast Error of } \Delta Y_{i, t: t+1}=\alpha+\lambda_{t}+\beta \text { Forecast of } \Delta F_{i, t: t+1 \mid t}+\varepsilon_{i, t: t+1} \text {, }
$$

where $t=2009,2010,2011$, and 2012. Based on the available data, the size of our European sample size is now 105 observations. Note, however, that for forecasts made in early 2011 and early 2012, the dependent variable is a forecast revision rather than a forecast error, since actual data for 2012 (included in the October 2012 WEO (IMF, 2012b), our reference) are not yet complete, and data for 2013 are not yet available. Results for these more recent forecasts should therefore be seen as preliminary. Given our use of two-year overlapping intervals, we correct the standard errors for serial correlation of type MA(1) using the Newey-West procedure. ${ }^{29}$

Table 4 reports the estimation results. For the panel of forecasts made during 2009-12, the estimate of $\beta$ is -0.667 ( $t$-statistic $=-4.143$ ), which is smaller than the baseline value obtained for forecasts made in early 2010 , but is still strongly statistically significant. Figure 2 illustrates this 2009-12 panel result using a scatter plot. ${ }^{30}$

Considering years individually, we find that the estimate of $\beta$ is statistically significant for forecasts made in early 2009, 2010, and 2012, but not for forecasts made in early 2011 . For the 2011 forecasts, the estimate of $\beta$ is -0.467 ( $t$-statistic $=-1.038)$. Thus, the concern, raised by some in reaction to the earlier version of this analysis, that the relation weakens for forecasts made in 2011 is warranted. ${ }^{31}$ For 2012, however, the estimate of $\beta$ is -0.357 ( $t$ statistic $=2.429$ ), which is statistically significant at the 5 percent level. This decline in the coefficient in 2011-12 to around -0.4 could reflect smaller multipliers or partial learning by forecasters regarding the effects of fiscal policy on economic activity. However, as explained above, results based on these more recent forecasts should be seen as preliminary. Once data for 2012-13 are complete, the estimation results for forecasts made in 2011-12 could be revisited. ${ }^{32}$

\footnotetext{
${ }^{29}$ The Newey West standard errors are larger than OLS standard errors in our application. They are obtained in STATA by choosing the option force of the newey command.

${ }^{30}$ As reported in Appendix Table 3, when controlling for the other variables discussed above, both sequentially (one at a time) and in a regression with all the controls included simultaneously, the estimate of $\beta$ for the full 2009-12 panel is similar to that reported in Table 4.

${ }^{31}$ Financial Times, October 12, 2012.

${ }^{32}$ As reported in Appendix Tables 4 and 5, the coefficients for the individual forecasts (for 2009-10, 2010-11, 2011-12, and 2012-13) are similar to, though typically less statistically significant, than those reported in Table 4 when estimated in a panel with different $\beta$ coefficients for each forecast, but now adding the additional controls discussed above both individually and simultaneously. Appendix Table 6 reports how the results hold
} 
Table 4 also reports estimation results based on the 2009-12 panel for our two alternative samples: the sample of all advanced economies and the sample of emerging market economies. For the broader sample of all advanced economies, the estimate of $\beta$ is -0.410 ( $t$-statistic $=-2.060)$, which is statistically significant at the 5 percent level. Figure 3 illustrates this 2009-12 result for advanced economies using a scatter plot, and suggests that the lower significance of this coefficient is again partly due to noise introduced by outliers. Also, as before, for the subset of advanced economies in a liquidity trap, the results are stronger: the 2009-12 panel estimate of $\beta$ is -0.648 ( $t$-statistic $=-3.042)$ and is significant at the 1 percent level. For emerging market economies, we again find no significant relation: the estimate of $\beta$ is -0.108 ( $t$-statistic $=-0.394)$.

How special is the crisis period? To address this question, Table 4 also reports the results of estimating equation (3) for the set of two-year intervals during the precrisis decade (19972008). We find no evidence of fiscal multipliers being underestimated, on average, during these more normal times. The estimate of $\beta$ is near zero, -0.077 ( $t$-statistic $=-0.470)$, for this period.

\section{EXTENSIONS}

Having discussed the robustness of our baseline results on a number of dimensions, we turn to three extensions. First, we check whether the baseline results differ depending on whether fiscal consolidation reflects changes in government spending or changes in revenue. Second, we consider the relation between planned fiscal consolidation and the forecast errors for the components of aggregate spending and for the unemployment rate. Third, we investigate whether the baseline results also hold when we rely on the forecast errors of other forecasters, including the EC, the OECD, and the EIU.

\section{A. Government Spending and Revenue}

To investigate whether the baseline results are driven primarily by spending cuts or by revenue increases, we split our measure of fiscal consolidation - the change in the structural fiscal balance - into the change in government spending and revenue. In particular, we estimate a modified version of our baseline equation, separating between the change in spending and the change in revenue: ${ }^{33}$

up to controlling for a summary statistic for economic and financial vulnerabilities based on the IMF's Early Warning Exercise vulnerability ratings, finding results similar to those reported in Table 4. In particular, the coefficients on the fiscal consolidation forecasts made during the 2009-12 period are all negative, and they are larger in absolute value and more statistically significant for the forecasts made in 2009-10 than in 2011-12.

${ }^{33}$ Since fiscal consolidation often involves a combination of spending cuts and tax hikes - they are correlatedincluding either alone would not be appropriate. 
Forecast Error of $\Delta Y_{i, t: t+1}=\alpha+\delta$ Forecast of $\Delta T_{i, t, t+1 \mid t}+\gamma$ Forecast of $\Delta S_{i, t, t+1 \mid t}+\varepsilon_{i, t: t+1}$

where $\Delta S_{i, t: t+1 \mid t}$ denotes the forecast of the change in structural spending in 2010-11 and $\Delta T_{i, t: t+1 \mid t}$ denotes the forecast of the change in structural revenue in 2010-11, both in percent of potential GDP. As before, the forecasts are taken from the April 2010 WEO (IMF, 2010c). IMF forecasts give forecasts of headline, not structural, spending. We construct forecasts for the change in structural spending based on the conventional assumption of a zero elasticity of government expenditure relative to the output gap (IMF, 2009a). Thus, we approximate the forecast for the change in the structural spending ratio to potential GDP by the forecast of the change in the headline spending ratio to potential GDP. The forecast for the change in structural revenue ratio to potential GDP is the sum of the forecast of the change in the structural fiscal balance and the forecast for the change in structural government spending: $\Delta T_{i, t: t+1 \mid t}=\Delta F_{i, t: t+1 \mid t}+\Delta S_{i, t: t+1 \mid t .}$

As Table 5 reports, the baseline results hold for both government spending and revenue. The point estimate of the coefficient on the forecast of government spending $(1.244, t$-statistic $=$ $4.989)$ is slightly larger in absolute value than the coefficient on the revenue forecast $(-0.865$, $t$-statistic $=-3.822$ ), but the difference is just short of being statistically insignificant ( $p$-value of 0.102 ) ${ }^{34}$ We estimate equation (3) using overall government spending or primary government spending (excluding interest payments), obtaining similar results. Overall, we conclude that fiscal multipliers were, on average, underestimated for both sides of the fiscal balance, with a slightly larger degree of underestimation associated with changes in government spending.

\section{B. Components of Aggregate Spending and Unemployment}

To get a sense of the sources of the growth forecast errors, we reestimate the baseline specification for the components of real GDP. For example, to investigate the relation between planned fiscal consolidation and forecast errors for private consumption growth, we estimate the following modification of our baseline equation:

$$
\text { Forecast Error of } \Delta C_{i, t: t+1}=\alpha+\beta \text { Forecast of } \Delta F_{i, t: t+1 \mid t}+\varepsilon_{i, t: t+1} \text {, }
$$

where Forecast Error of $\Delta C_{i, t: t+1}$ is the forecast error for real private consumption growth, instead of real GDP growth as in the baseline.

\footnotetext{
${ }^{34}$ The regression coefficient for spending is positive, indicating that spending cuts (negative changes in spending) were associated with negative GDP forecast errors.
} 
As Table 6 reports, when we decompose the effect on GDP in this way, we find that planned fiscal consolidation is associated with significantly lower-than-expected consumption and investment growth. The coefficient for investment growth $(-2.681)$ is about three times larger than that for private consumption growth $(-0.816)$, which is consistent with research showing that investment varies relatively strongly in response to overall economic conditions. For example, based on U.S. data, Romer and Romer (2010) find that, in response to a tax increase, GDP, investment and consumption all decline, but investment growth falls by about four times more than consumption growth does. Conventional models predict that fiscal consolidation is normally associated with lower interest rates, supporting investment. The fact that investment growth falls by more than expected in response to fiscal consolidation could reflect the lack of the conventional interest rate effect during this period. In contrast, the results for export and import growth are not statistically significant.

Since lower-than-expected output growth could be expected to reduce inflation pressure, we also look at the forecast error for the GDP deflator, finding evidence of a negative, but statistically insignificant, relation. When we repeat the exercise for the unemployment rate, we find a coefficient of 0.608 , which is statistically and economically significant. Overall, we find that, for the baseline sample, forecasters significantly underestimated the increase in unemployment and the decline in domestic demand associated with fiscal consolidation.

\section{Alternative Forecasts}

Finally, we compare the baseline results obtained for IMF forecast errors with those obtained for the forecast errors of other forecasters, including the EC, the OECD, and the EIU. Data for EC forecasts of both the structural fiscal balance and real GDP are from the spring 2010 European Economic Forecast (EC, 2010). Data for OECD forecasts of the structural fiscal balance and real GDP are from the May 2010 Economic Outlook (OECD, 2010). Data for EIU forecasts of real GDP are from the April 2010 Country Forecast (EIU, 2010). Since the EIU does not publish forecasts of the structural fiscal balance, we take forecasts of fiscal consolidation from the April 2010 WEO (IMF, 2010c) for the EIU regressions. We estimate the regressions for our baseline sample, both for all the forecasts available from each forecast source and for a (smaller) subsample for which the economies included are the same in each regression. As Table 7 reports, we find that the baseline result of a negative relation between growth forecast errors and planned fiscal consolidation holds for all the forecasters considered, but that it is strongest in terms of both economic and statistical significance for IMF forecasts, and, to a slightly smaller extent, for EC forecasts. 


\section{CONCLUSiOnS}

What do our results imply about actual multipliers? Our results suggest that actual fiscal multipliers have been larger than forecasters assumed. But what did forecasters assume? Answering this question is not easy, since forecasters use models in which fiscal multipliers are implicit and depend on the composition of the fiscal adjustment and other economic conditions. ${ }^{35}$

We believe, however, that a reasonable case can be made that the multipliers used at the start of the crisis averaged about 0.5 . A number of studies based on precrisis data for advanced economies indicate actual multipliers of roughly 0.5 , and it is plausible that forecasters, on average, made assumptions consistent with this evidence. The October 2008 WEO chapter on fiscal policy presents multiplier estimates for 21 advanced economies during 1970-2007 averaging 0.5 within three years (IMF, 2008, p. 177). Similarly, the October 2010 WEO (IMF, 2010d) chapter on fiscal consolidation presents multiplier estimates for 15 advanced economies during 1979-2009 averaging 0.5 percent within two years. ${ }^{36}$ This evidence, and our finding of no gap, on average, between assumed and actual fiscal multipliers before the crisis, would imply that multipliers assumed prior to the crisis were around 0.5. Relatedly, the March 2009 IMF staff note prepared for the G-20 Ministerial Meeting reports IMF staff assumptions regarding fiscal multipliers based on estimates from various studies. In particular, it contains an assessment of the impact of the 2008-10 fiscal expansion on growth based on assumed multipliers of $0.3-0.5$ for revenue and $0.3-1.8$ for government spending (IMF, 2009b, p. 32). ${ }^{37}$

If we put this together, and use the range of coefficients reported in our tables, this suggests that actual multipliers were substantially above 1 early in the crisis. The smaller coefficient we find for forecasts made in 2011 and 2012 could reflect smaller actual multipliers or partial learning by forecasters regarding the effects of fiscal policy. A decline in actual multipliers, despite the still-constraining zero lower bound, could reflect an easing of credit constraints

\footnotetext{
${ }^{35}$ Note that inferring assumed multipliers from regressions of growth forecasts on forecasts of the fiscal policy stance is not possible. For example, economies with a worse economic outlook may have planned more fiscal stimulus, and a regression of growth forecasts on forecasts of the fiscal policy stance may thus, incorrectly, suggest that assumed multipliers were near zero or even negative.

${ }^{36}$ A survey of the literature provided by Spilimbergo, Symansky, and Schindler (2009) indicated a wide range of multiplier estimates, which includes 0.5 but which points, for the most part, to somewhat higher multipliers.

${ }^{37}$ The December 2010 OECD Economic Outlook includes a table on the likely effects of fiscal consolidation on GDP, suggesting multipliers closer to 1 for a package equally composed of spending cuts and direct tax increases. Such higher multipliers, if they were used in forecasting, may help to explain our finding of a smaller coefficient on fiscal consolidation forecasts for OECD growth forecast errors.
} 
faced by firms and households, and less economic slack in a number of economies relative to 2009-10.

However, our results need to be interpreted with care. As suggested by both theoretical considerations and the evidence in this and other empirical papers, there is no single multiplier for all times and all countries. Multipliers can be higher or lower across time and across economies. In some cases, confidence effects may partly offset direct effects. As economies recover, and economies exit the liquidity trap, multipliers are likely to return to their precrisis levels. Nevertheless, it seems safe for the time being, when thinking about fiscal consolidation, to assume higher multipliers than before the crisis.

Finally, it is worth emphasizing that deciding on the appropriate stance of fiscal policy requires much more than an assessment regarding the size of short-term fiscal multipliers. Thus, our results should not be construed as arguing for any specific fiscal policy stance in any specific country. In particular, the results do not imply that fiscal consolidation is undesirable. Virtually all advanced economies face the challenge of fiscal adjustment in response to elevated government debt levels and future pressures on public finances from demographic change. The short-term effects of fiscal policy on economic activity are only one of the many factors that need to be considered in determining the appropriate pace of fiscal consolidation for any single country. 


\section{Appendix}

This appendix reports how the baseline results are affected by the inclusion of ex-post variables in the specification (Appendix Table 1); how the results for the broader sample of all advanced economies change when controlling for other variables (Appendix Table 2); how the panel results for different year intervals in 2009-12 are influenced by the inclusion of additional controls, both individually and simultaneously (Appendix Tables 3, 4, and 5); and how the results hold up to controlling for a summary statistic for economic and financial vulnerabilities based on the IMF's Early Warning Exercise (EWE) ratings (Appendix Table 6).

Appendix Table 1 reports the results of controlling for variables that were not known at the time forecasts were made. We do so because some commentators have run such regressions, and we want to report the results using our sample. As discussed above, however, we do not think these regressions can shed light on the question of whether forecasters underestimated fiscal multipliers or on the role of some other factor. Even if controlling for such variables significantly changed the estimate of $\beta$, the coefficient would no longer have an economic interpretation.

We start by considering the increase in sovereign and financial market stress during 2010-11, measured by the change in CDS spreads from 2010:Q1 to 2011:Q4. As Appendix Table 2 reports, controlling for the change in sovereign CDS spreads during 2010-11 yields a $\beta$ estimate of -0.839 ( $t$-statistic $=-2.797)$, which is not statistically distinguishable from our baseline estimate of -1.095 . Controlling for the change in bank CDS spreads over the same time period yields a $\beta$ estimate of $-1.002(t$-statistic $=-4.158) .{ }^{38} \mathrm{Next}$, we control for the revision to the initial (end-2009) government debt-to-GDP ratio. If subsequent upward revisions to the initial stock of debt caused a rise in borrowing costs and lower growth, the revision to the initial debt stock could be correlated with growth forecast errors. However, we find that controlling for this revision — as measured by the latest estimates of the end-2009 government debt-to-GDP ratio minus the spring 2010 estimate-yields a $\beta$ estimate of $1.090(t$-statistic $=-4.395)$, which is again similar to the baseline.

Finally, controlling for unexpected fiscal consolidation (the fiscal consolidation forecast error) does not significantly affect the results. The estimate of $\beta$ is -1.077 ( $t$-statistic $=-$ 5.033 ) in this case, which indicates that the omission of this variable from the baseline specification was not a significant source of bias. ${ }^{39}$ The coefficient on the forecast error of

\footnotetext{
${ }^{38}$ As before, we fill the 11 missing observations for the change in bank CDS spreads using the predicted values from a regression of the change in bank CDS spreads on the change in sovereign CDS spreads during 2010$11-$ a strong relation with a slope coefficient of $0.931(t$-statistic $=22.370)$.

${ }^{39}$ In response to comments on an earlier version of this paper (EC, 2012), we also reestimate equation (1) while allowing the coefficients $\beta$ and $\alpha$ to be different for the group of economies that, in ex-post terms, undertook
}

(continued...) 
fiscal consolidation is small and statistically insignificant $(-0.309$ with a $t$-statistic of 1.626), but, as discussed above, this estimate suffers from two-way causality, and thus cannot be given a structural interpretation. Over the two-year intervals we consider, changes in fiscal policy are unlikely to be orthogonal to economic developments. Thus, the forecast error of fiscal consolidation cannot be interpreted as an identified fiscal shock.

Appendix Table 2 reports the results of repeating the analysis reported in Table 2 for the broader group of all advanced economies. The results are consistent with those reported in Table 1. In particular, based on OLS, which is strongly influenced by outliers in this sample, the estimate of $\beta$ is negative but statistically insignificant for each case of adding an additional control variable. But using the robust regression approach, which resists the pull of outliers, the estimate of $\beta$ is statistically significant in each case, and is typically above 0.9 in absolute value.

Appendix Table 3 reports the results of estimating the panel data specification, equation (2), while controlling for the additional variables reported in earlier (in Table 2). We add the additional controls both one at a time, and simultaneously in a large-scale regression with 12 control variables (columns 14 and 15). The coefficient $\beta$ remains significant in each case, and ranges from -0.447 to -0.712 , compared to an estimate of -0.667 for the baseline specification without controls. Overall, the panel data results also hold up to controlling for these other variables.

Appendix Table 4 is the same as Appendix Table 3, except that the estimate of $\beta$ is allowed to vary across the forecast vintages $(2009,2010,2011$, and 2012). As before, given our use of two-year overlapping intervals, we correct the standard errors for serial correlation of type MA(1) using the Newey-West procedure. The coefficient for forecasts made in 2009 and 2010 is about -0.6 and -1 , respectively, and remain statistically significant in all specifications. The coefficient for forecasts made in 2011 and 2012 is negative, and typically around -0.4 and -0.3 , respectively. For the 2011 forecasts, the coefficient is statistically insignificant, as before. For the forecasts made in 2012, the coefficient is significant in some specifications, and not in others.

Appendix Table 5 reports the results of a similar exercise, in which both the coefficient on the fiscal consolidation forecast and on each additional control is allowed to vary over time. Allowing the coefficient on the controls to vary over time yields estimates for the coefficients on the fiscal consolidation forecasts that are similar to those reported in earlier tables.

fiscal stimulus in $2010\left(\Delta F_{i, 2010}<0\right)$ and fiscal consolidation in $2011\left(\Delta F_{i, 2011}>0\right)$, using dummy variables. We fail to reject the null hypothesis that the coefficient $\beta$ is the same for this group as for the rest $(p$-value $=0.772$ ). The estimate of $\beta$ for this group is -1.058 ( $t$-statistic $=-2.990$ ), and the estimate of $\beta$ for the remaining economies is $-1.223(t$-statistic $=-2.800)$. 
As one can always think of more controls, and eventually exhaust degrees of freedom, Appendix Table 6 takes a different approach. It explores how the results change when we control for a summary statistic for various economic and financial vulnerabilities perceived at the time the forecasts were made. The summary statistic we use is the IMF's vulnerability rating prepared for each advanced economy as part of the Early Warning Exercise (EWE). As explained in the methodological guide to these ratings (IMF, 2010c), each economy's vulnerability rating is based on underlying risk assessments made for different economic sectors, such as the external, government, corporate, and household sectors. As before, to ensure that the vulnerability ratings provide a measure of risks forecasters may have perceived in real time, while making the forecasts, we use the spring 2009 EWE ratings for the 2009 forecasts, the spring 2010 EWE ratings for the 2010 forecasts, and so on. Since the EWE vulnerability ratings are confidential, we report the regression results based on them in Appendix Table 6, but cannot include the actual underlying ratings in the replication dataset discussed above. As the table reports, the estimation results are similar to those reported above. In particular, the coefficients on the fiscal consolidation forecasts made during the 2009-12 period are all negative, and they are larger in absolute value and more statistically significant for the forecasts made in 2009-10 than in 2011-12. 


\section{References}

Almunia, Miguel, Agustin Benetrix, Barry Eichengreen, Kevin O'Rourke, and Gisela Rua, 2010, "From Great Depression to Great Credit Crisis: Similarities, Differences and Lessons," Economic Policy, Vol. 25.

Andersen, Robert, 2008, Modern Methods for Robust Regression (Thousand Oaks, California: SAGE Publications).

Auerbach, Alan, and Yuriy Gorodnichenko, 2012a, "Fiscal Multipliers in Recession and Expansion," in Fiscal Policy after the Financial Crisis, edited by Alberto Alesina and Francesco Giavazzi (Chicago: University of Chicago Press).

- 2012b, "Measuring the Output Responses to Fiscal Policy," American Economic Journal-Economic Policy, Vol. 4, pp. 1-27.

— 2012c, “Output Spillovers from Fiscal Policy,” NBER Working Paper No. 18578 (Cambridge, Massachusetts: National Bureau of Economic Research).

Batini, Nicoletta, Giovanni Callegari, and Giovanni Melina, 2012, "Successful Austerity in the United States, Europe and Japan,” IMF Working Paper No. 12/190 (Washington: International Monetary Fund).

Baum, Anja, Marcos Poplawski-Ribeiro, and Anke Weber, 2012, "Fiscal Multipliers and the State of the Economy," IMF Working Paper No. 12/286 (Washington: International Monetary Fund).

Christiano, Lawrence, Martin Eichenbaum, and Sergio Rebelo, 2011, "When Is the Government Spending Multiplier Large?” Journal of Political Economy, Vol. 119, pp. $78-121$.

Coenen, Günter, Christopher Erceg, Charles Freedman, Davide Furceri, Michael Kumhof, René Lalonde, Douglas Laxton, Jesper Lindé, Annabelle Mourougane, Dirk Muir, Susanna Mursula, John Roberts, Werner Roeger, Carlos de Resende, Stephen Snudden, Mathias Trabandt, Jan in't Veld, 2012, "Effects of Fiscal Stimulus in Structural Models," American Economic Journal: Macroeconomics, Vol. 4, No. 1, pp. 22-68.

Cottarelli, Carlo, and Laura Jaramillo, 2012, "Walking Hand in Hand: Fiscal Policy and Growth in Advanced Economies," IMF Working Paper No. 12/137 (Washington: International Monetary Fund). 
Economist Intelligence Unit (EIU), 2010, Country Forecast (London, April, various countries).

Eggertsson, Gauti B., and Paul Krugman, 2012, "Debt, Deleveraging, and the Liquidity Trap," Quarterly Journal of Economics, pp. 1469-513.

Eichengreen, Barry, and Kevin H O'Rourke, 2012, "Gauging the Multiplier: Lessons from History," Vox EU (23 October).

European Commission (EC), 2010, European Economic Forecast-Spring 2010

(Luxembourg: Publications Office of the European Union).

— 2012, European Economic Forecast—Autumn 2012. (Luxembourg: Publications Office of the European Union).

Financial Times, 2012, “Robustness of IMF Data Scrutinized,” October 12.

Hall, Robert E., 2009, "By How Much Does GDP Rise If the Government Buys More Output?" Brookings Papers on Economic Activity, Fall, pp. 183-249.

Hamilton, Lawrence C., 2012, Statistics with STATA: Version 12 (Belmont, California: Duxbury Press).

International Monetary Fund, 2008, World Economic Outlook: Financial Stress,Downturns, and Recoveries (Washington: International Monetary Fund, October).

International Monetary Fund, 2009a, "Computing Cyclically Adjusted Balances and Automatic Stabilizers," Technical Guidance Note (Washington: International Monetary Fund, November).

International Monetary Fund, 2009b, "Global Economic Policies and Prospects," Note by the Staff of the International Monetary Fund (Washington: International Monetary Fund).

International Monetary Fund, 2010a, "The IMF-FSB Early Warning Exercise—Design and Methodological Toolkit" (Washington: International Monetary Fund).

International Monetary Fund, 2010b, Singapore: 2010 Article IV Consultation-Staff Report (Washington: International Monetary Fund).

International Monetary Fund, 2010c, World Economic Outlook: Rebalancing Growth (Washington: International Monetary Fund, April). 
International Monetary Fund, 2010d, World Economic Outlook: Recovery, Risk, and Rebalancing (Washington: International Monetary Fund, October).

International Monetary Fund, 2012a, Fiscal Monitor: Balancing Fiscal Policy Risks (Washington: International Monetary Fund, April).

International Monetary Fund, 2012b, World Economic Outlook: Coping with High Debt and Sluggish Growth (Washington: International Monetary Fund, October).

International Monetary Fund, 2012c, World Economic Outlook: Growth Resuming, Dangers Remain (Washington: International Monetary Fund, April).

Lane, Philip R., and Gian Maria Milesi-Ferretti, 2007, “The External Wealth of Nations Mark II: Revised and Extended Estimates of Foreign Assets and Liabilities, 19702004," Journal of International Economics, Vol. 73, pp. 223-50.

Laeven, Luc, and FabiánValencia, 2012, "Systemic Banking Crises Database: An Update," IMF Working Paper No. 12/163 (Washington: International Monetary Fund).

Mian, Atif, Kamalesh Rao, and Amir Sufi, 2011, "Household Balance Sheets, Consumption, and the Economic Slump," University of Chicago Booth School of Business Working Paper (Chicago).

Organization for Economic Cooperation and Development (OECD), 2010, Economic Outlook, Vol. 2010, No. 1 (Paris, May).

Romer, Christina, and David Romer, 2010, "The Macroeconomic Effects of Tax Changes: Estimates Based on a New Measure of Fiscal Shocks," American Economic Review, June.

Romer, Christina, 2012, "Fiscal Policy in the Crisis: Lessons and Policy Implications," presented at the IMF Fiscal Forum, April 18, Washington.

Spilimbergo, Antonio, Steve Symansky, and Martin Schindler, 2009, "Fiscal Multipliers," IMF Staff Position Note No. 09/11 (Washington: International Monetary Fund).

Woodford, Michael, 2011, "Simple Analytics of the Government Expenditure Multiplier," American Economic Journal: Macroeconomics, Vol. 3, No. 1, pp. 1-35. 
Table 1. Main Results

Equation: Forecast Error of $\Delta Y_{i, t: t+1}=\alpha+\beta$ Forecast of $\Delta F_{i, t: t+1 \mid t}+\varepsilon_{i, t: t+1}$

\begin{tabular}{|c|c|c|c|c|c|c|}
\hline & $\beta$ & & $\alpha$ & & Obs & $R^{2}$ \\
\hline \multicolumn{7}{|l|}{ Europe } \\
\hline Baseline & $-1.095 * * *$ & $(0.255)$ & $0.775^{*}$ & $(0.383)$ & 26 & 0.496 \\
\hline Filling missing using EC forecasts & $-1.074 * * *$ & $(0.294)$ & $1.034 * *$ & $(0.454)$ & 30 & 0.403 \\
\hline Excluding 2 largest policy changes & $-0.776 * *$ & $(0.345)$ & 0.690 & $(0.405)$ & 24 & 0.227 \\
\hline Excluding IMF programs & $-0.812 * * *$ & $(0.281)$ & $0.859 * *$ & $(0.381)$ & 21 & 0.235 \\
\hline Excluding Emerging Europe & $-0.992 * * *$ & $(0.278)$ & $0.832 *$ & (0.416) & 22 & 0.475 \\
\hline Outliers: Robust regression & $-1.279 * * *$ & (0.183) & $0.606^{*}$ & $(0.317)$ & 26 & 0.671 \\
\hline Outliers: Quantile regression & $-1.088 * * *$ & $(0.240)$ & 0.510 & $(0.410)$ & 26 & 0.262 \\
\hline Outliers: Cook's Distance & $-0.921 * * *$ & $(0.217)$ & $0.738^{* * *}$ & $(0.247)$ & 21 & 0.539 \\
\hline \multicolumn{7}{|l|}{ Advanced economies } \\
\hline All available & -0.538 & $(0.407)$ & 0.696 & $(0.450)$ & 36 & 0.097 \\
\hline Economies in liquidity trap & $-0.986 * * *$ & $(0.270)$ & 0.415 & $(0.282)$ & 23 & 0.599 \\
\hline Outliers: Robust regression & $-0.955^{* * *}$ & $(0.201)$ & 0.540 & $(0.342)$ & 36 & 0.400 \\
\hline Outliers: Quantile regression & $-0.999 * * *$ & $(0.127)$ & $0.486^{* *}$ & $(0.216)$ & 36 & 0.0991 \\
\hline Outliers: Cook's Distance & $-0.746 * *$ & $(0.279)$ & $0.792 * *$ & $(0.328)$ & 33 & 0.211 \\
\hline \multicolumn{7}{|l|}{ Emerging economies } \\
\hline All available & 0.007 & $(0.433)$ & 1.791 & (1.271) & 14 & 0.000 \\
\hline Outliers: Robust regression & 0.168 & $(0.228)$ & 0.291 & $(0.466)$ & 14 & 0.043 \\
\hline Outliers: Quantile regression & 0.313 & $(0.355)$ & 0.310 & (0.791) & 14 & 0.0312 \\
\hline Outliers: Cook's Distance & -0.143 & $(0.230)$ & 1.364 & $(0.875)$ & 12 & 0.004 \\
\hline
\end{tabular}

Note: Table reports point estimates and heteroskedasticity-robust standard errors in parentheses. ***, **, and * denote statistical significance at the 1,5, and 10 level, respectively. Robust regression downweights observations with larger absolute residuals using iterative weighted least squares (Andersen, 2008). 
Table 2. Europe: Robustness to Additional Controls

Equation: Forecast Error of $\Delta Y_{i, t: t+1}=\alpha+\beta$ Forecast of $\Delta F_{i, t: t+1 \mid t}+\gamma X_{i, t \mid t}+\varepsilon_{i, t: t+1}$

\begin{tabular}{|c|c|c|c|c|c|}
\hline Additional Control & $\beta$ & $\gamma$ & & Obs & $R^{2}$ \\
\hline Baseline & $-1.095 * * *(0.255)$ & & & 26 & 0.496 \\
\hline Initial debt ratio & $-1.146 * * * \quad(0.270)$ & 0.010 & $(0.013)$ & 26 & 0.504 \\
\hline Initial fiscal balance & $-1.173 * * * \quad(0.299)$ & -0.045 & $(0.068)$ & 26 & 0.500 \\
\hline Initial structural fiscal balance & $-0.921 * * \quad(0.360)$ & 0.115 & $(0.187)$ & 26 & 0.506 \\
\hline Initial sovereign CDS & $-0.990 * * * \quad(0.296)$ & -0.259 & $(0.458)$ & 26 & 0.504 \\
\hline Initial bank CDS & $-1.007 * * * \quad(0.281)$ & -0.208 & $(0.383)$ & 26 & 0.502 \\
\hline Banking crisis & $-1.105^{* * *}(0.262)$ & 0.162 & $(0.773)$ & 26 & 0.497 \\
\hline Initial growth forecast & $-1.099 * * * \quad(0.275)$ & -0.008 & $(0.178)$ & 26 & 0.496 \\
\hline Initial potential growth forecast & $-1.126 * * *(0.251)$ & -0.242 & $(0.177)$ & 26 & 0.524 \\
\hline Trading partner fiscal consolidation & $-1.105^{* * *}(0.270)$ & -0.548 & $(1.343)$ & 26 & 0.499 \\
\hline Precrisis current account balance & $-0.935 * * *(0.274)$ & 0.060 & $(0.049)$ & 26 & 0.531 \\
\hline Precrisis net foreign liabilities & $-1.056 * * *(0.306)$ & -0.002 & $(0.006)$ & 26 & 0.498 \\
\hline Precrisis household debt & $-1.086 * * * \quad(0.262)$ & -0.001 & $(0.006)$ & 25 & 0.489 \\
\hline
\end{tabular}

Note: Table reports point estimates and heteroskedasticity-robust standard errors in parentheses. ***,**, and * denotes statistical significance at the 1,5, and 10 level, respectively. Constant term included in specification but estimate not reported. The additional controls appear in the specifications one at a time. 
Table 3. Europe: Two-stage Least Squares

First stage: $\Delta F_{i, t: t+1}=\gamma+\delta$ Forecast of $\Delta F_{i, t: t+1 \mid t}+\eta_{i, t: t+1}$

Second stage: Forecast Error of $\Delta Y_{i, t: t+1}=\alpha+\beta \Delta \hat{F}_{i, t: t+1}+\varepsilon_{i, t: t+1}$

\begin{tabular}{llc}
\hline & & \\
& First stage & Second stage \\
\hline & & \\
& & \\
& & \\
$\beta$ & $\left(0.1857^{* * *}\right.$ & \\
& & $-1.036^{* * *}$ \\
Constant term & $0.907^{* * *}$ & $(0.228)$ \\
& $(0.320)$ & $1.715^{* * *}$ \\
& & $(0.548)$ \\
Obs & 26 & 26 \\
$R^{2}$ & 0.578 & 0.350 \\
& & \\
\hline
\end{tabular}

Note: Table reports point estimates and heteroskedasticity-robust standard errors in parentheses. ***, **, and * denotes statistical significance at the 1,5 , and 10 level, respectively. ${ }^{\wedge}$ denotes instrumented values. 
Table 4. 2009-12 Panel of Forecasts

Equation: Forecast Error of $\Delta Y_{i, t: t+1}=\alpha+\lambda_{t}+\beta$ Forecast of $\Delta F_{i, t: t+1 \mid t}+\varepsilon_{i, t: t+1}$

\begin{tabular}{|c|c|c|c|c|}
\hline & \multicolumn{2}{|l|}{$\beta$} & \multirow[t]{2}{*}{ Obs } & \multirow[t]{2}{*}{$R^{2}$} \\
\hline Europe & & & & \\
\hline $2009-10$ to $2012-13$ & $-0.667^{* * *}$ & $(0.161)$ & 105 & 0.413 \\
\hline \multicolumn{5}{|l|}{ Results for forecasts for: } \\
\hline $2009-10$ & $-0.699 * * *$ & $(0.185)$ & 26 & 0.208 \\
\hline $2010-11$ & $-1.095 * * *$ & $(0.255)$ & 26 & 0.496 \\
\hline 2011-12 & -0.467 & $(0.450)$ & 25 & 0.091 \\
\hline $2012-13$ & $-0.358 * *$ & $(0.147)$ & 28 & 0.194 \\
\hline $1997-98$ to $2008-09$ & -0.077 & $(0.164)$ & 207 & 0.640 \\
\hline \multicolumn{5}{|l|}{ Advanced economies } \\
\hline \multicolumn{5}{|l|}{$2009-10$ to $2012-13$} \\
\hline All available & $-0.410 * *$ & (0.199) & 145 & 0.286 \\
\hline Economies in liquidity trap & $-0.648^{* * *}$ & $(0.213)$ & 94 & 0.440 \\
\hline \multicolumn{5}{|l|}{ Emerging market economies } \\
\hline $2009-10$ to $2012-13$ & -0.108 & $(0.274)$ & 54 & 0.362 \\
\hline
\end{tabular}

Note: Table reports point estimates and Newey-West standard errors in parentheses (correcting for heteroskedasticity and autocorrelation up to one year). ***,**, and * denotes statistical significance at the 1,5 , and 10 level, respectively. Constant term and time-fixed effects included in all panel regressions, but estimates not reported. 
Table 5. Europe: Government Revenue and Spending Equation estimated:

Forecast Error of $\Delta Y_{i, t: t+1}=\alpha+\delta$ Forecast of $\Delta T_{i, t: t+1 \mid t}+\gamma$ Forecast of $\Delta S_{i, t: t+1 \mid t}+\varepsilon_{i, t: t+1}$

Forecast Error of $\Delta Y, i: t+1$

(2)

\begin{tabular}{lcc}
\hline \&: Forecast of $\Delta T_{i, t: t+1 \mid t}$ & $-0.865^{* * *}$ & $-0.783^{* * *}$ \\
& $(0.225)$ & $(0.221)$ \\
v: Forecast of $\Delta S_{i, t: t+1 \mid t}$ & $1.244^{* * *}$ & \\
& $(0.254)$ & \\
y: Forecast of $\Delta S$ (primary) $i, t: t+1 \mid t$ & & $1.179^{* * *}$ \\
& & $(0.243)$ \\
$\alpha$ & $0.807^{* *}$ & $1.140^{* * *}$ \\
& $(0.373)$ & $(0.389)$ \\
& & \\
Obs & 26 & 26 \\
$R^{2}$ & 0.554 & 0.557 \\
$p$ - value $(\delta+\gamma=0)$ & 0.102 & 0.095 \\
& & \\
\hline
\end{tabular}

Note: Table reports point estimates and heteroskedasticity-robust standard errors in parentheses. ${ }^{* *}, * *$, and $*$ denotes statistical significance at the 1,5, and 10 level, respectively. $T$ denotes government revenue, and $S$ denotes government spending. $p$-value is for test of null that $\delta+\gamma=0$. 
Table 6. Europe: Unemployment and GDP Components

Equation: Forecast Error of $\Delta Y_{i, t: t+1}=\alpha+\beta$ Forecast of $\Delta F_{i, t: t+1 \mid t}+\varepsilon_{i, t: t+1}$

\begin{tabular}{|c|c|c|c|c|c|c|}
\hline Dependent Variable $(Y)$ & $\beta$ & & $\alpha$ & & Obs & $R^{2}$ \\
\hline GDP & $-1.095 * * *$ & $(0.255)$ & $0.775^{*}$ & (0.383) & 26 & 0.496 \\
\hline Private consumption & $-0.816 * * *$ & $(0.138)$ & -0.620 & $(0.388)$ & 26 & 0.330 \\
\hline Investment & $-2.681 * * *$ & $(0.910)$ & -2.580 & (1.993) & 26 & 0.174 \\
\hline Exports & -1.109 & $(0.925)$ & $8.866^{* * *}$ & $(1.442)$ & 26 & 0.070 \\
\hline Imports & -0.639 & $(1.006)$ & $6.520 * * *$ & (1.665) & 26 & 0.025 \\
\hline GDP Deflator & -0.185 & $(0.253)$ & 0.286 & $(0.425)$ & 26 & 0.016 \\
\hline Unemployment rate & $0.608 * * *$ & (0.193) & -0.179 & (0.336) & 26 & 0.270 \\
\hline
\end{tabular}

Note: Table reports point estimates and heteroskedasticity-robust standard errors in parentheses. ***, **, and * denotes statistical significance at the 1,5 , and 10 level, respectively. 
Table 7. Europe: Alternative Forecasters

Equation: Forecast Error of $\Delta Y_{i, t: t+1}=\alpha+\beta$ Forecast of $\Delta F_{i, t: t+1 \mid t}+\varepsilon_{i, t: t+1}$

\begin{tabular}{|c|c|c|c|c|c|}
\hline Source of Forecasts & $\beta$ & $\alpha$ & & Obs & $R^{2}$ \\
\hline IMF & $-1.095 * * * \quad(0.255)$ & $0.775^{*}$ & $(0.383)$ & 26 & 0.496 \\
\hline European Commission & $-0.837^{* *} \quad(0.358)$ & 0.728 & $(0.461)$ & 27 & 0.291 \\
\hline OECD & $-0.371 * * *(0.125)$ & 0.199 & (0.449) & 21 & 0.274 \\
\hline Economist Intelligence Unit & $-0.696 * * \quad(0.318)$ & $1.116^{*}$ & $(0.565)$ & 22 & 0.220 \\
\hline \multicolumn{6}{|l|}{ Equalized sample } \\
\hline IMF & $-1.129 * * * \quad(0.304)$ & $1.259 * *$ & $(0.506)$ & 17 & 0.539 \\
\hline European Commission & $-0.900 * \quad(0.449)$ & 0.430 & $(0.526)$ & 17 & 0.391 \\
\hline OECD & $-0.531 * * * \quad(0.121)$ & 0.509 & $(0.482)$ & 17 & 0.419 \\
\hline Economist Intelligence Unit & $-0.773 * * * \quad(0.245)$ & $1.930 * * *$ & $(0.467)$ & 17 & 0.407 \\
\hline
\end{tabular}

Note: Table reports point estimates and heteroskedasticity-robust standard errors in parentheses. ${ }^{* *},{ }^{* *}$, and ${ }^{*}$ denotes statistical significance at the 1,5 , and 10 level, respectively. 
Appendix Table 1. Europe: Controlling for Ex-post Developments

Equation: Forecast Error of $\Delta Y_{i, t: t+1}=\alpha+\beta$ Forecast of $\Delta F_{i, t: t+1 \mid t}+\gamma X_{i, t+1}+\varepsilon_{i, t: t+1}$

\begin{tabular}{|c|c|c|c|c|c|c|}
\hline Additional Control & $\beta$ & & $\gamma$ & & Obs & $R^{2}$ \\
\hline Baseline & $-1.095^{* * *}$ & $(0.255)$ & & & 26 & 0.496 \\
\hline Ex-post change in sovereign CDS & $-0.839 * *$ & $(0.300)$ & $-0.054^{* *}$ & $(0.023)$ & 26 & 0.548 \\
\hline Ex-post change in bank CDS & $-1.002 * * *$ & $(0.241)$ & -0.100 & (0.135) & 26 & 0.509 \\
\hline Revision to initial debt ratio & $-1.090 * * *$ & $(0.248)$ & -0.026 & $(0.056)$ & 26 & 0.499 \\
\hline Unexpected fiscal consolidation & $-1.077 * * *$ & $(0.214)$ & -0.309 & $(0.190)$ & 26 & 0.528 \\
\hline
\end{tabular}

Note: Table reports point estimates and heteroskedasticity-robust standard errors in parentheses. ***, **, and * denotes statistical significance at the 1,5, and 10 level, respectively. Constant term included in specification but estimates not reported. The additional controls appear in the specifications one at a time. 
Appendix Table 2. All Advanced Economies: Robustness to Additional Controls Equation: Forecast Error of $\Delta Y_{i, t: t+1}=\alpha+\beta$ Forecast of $\Delta F_{i, t: t+1 \mid t}+\gamma X_{i, t \mid t}+\varepsilon_{i, t: t+1}$

\begin{tabular}{|c|c|c|c|c|c|c|}
\hline \multirow[b]{2}{*}{ Additional Control } & \multicolumn{2}{|l|}{ OLS Regression } & \multicolumn{4}{|c|}{ Robust Regression } \\
\hline & $\beta$ & Obs & $R^{2}$ & $\beta$ & Obs & $R^{2}$ \\
\hline Baseline & $-0.538(0.407)$ & 36 & 0.097 & $-0.955^{* * *}(0.201)$ & 36 & 0.400 \\
\hline Initial debt ratio & $-0.577(0.403)$ & 36 & 0.102 & $-0.967 * * * \quad(0.234)$ & 35 & 0.432 \\
\hline Initial fiscal balance & $-0.277(0.509)$ & 36 & 0.156 & $-0.956 * * *(0.272)$ & 35 & 0.431 \\
\hline Initial structural fiscal balance & $0.013 \quad(0.476)$ & 36 & 0.256 & $-0.729 * * * \quad(0.261)$ & 35 & 0.464 \\
\hline Initial sovereign CDS & $-0.534(0.395)$ & 33 & 0.250 & $-0.919 * * * \quad(0.254)$ & 33 & 0.455 \\
\hline Initial bank CDS & $-0.543(0.387)$ & 33 & 0.249 & $-0.921 * * *(0.241)$ & 33 & 0.455 \\
\hline Banking crisis & $-0.495(0.421)$ & 36 & 0.110 & $-0.960 * * * \quad(0.231)$ & 35 & 0.432 \\
\hline Initial growth forecast & $-0.396(0.400)$ & 36 & 0.208 & $-0.920 * * * \quad(0.239)$ & 35 & 0.436 \\
\hline Initial potential growth forecast & $-0.515(0.400)$ & 36 & 0.192 & $-0.946 * * * \quad(0.238)$ & 35 & 0.433 \\
\hline Trading partner fiscal consolidation & $-0.451(0.442)$ & 36 & 0.145 & $-0.961 * * *(0.255)$ & 35 & 0.431 \\
\hline Precrisis current account balance & $-0.249(0.313)$ & 36 & 0.461 & $-0.784 * * *(0.255)$ & 35 & 0.475 \\
\hline Precrisis net foreign liabilities & $-0.260(0.361)$ & 36 & 0.352 & $-0.817^{* * *}(0.290)$ & 35 & 0.455 \\
\hline
\end{tabular}

Note: Table reports point estimates and heteroskedasticity-robust standard errors in parentheses. $* * *, * *$, and * denotes statistical significance at the 1,5, and 10 level, respectively. Estimation results for coefficient on additional control $(\gamma)$ and constant term not reported. Robust regressions use same weights as baseline regression (row 1). The additional controls appear in the specifications one at a time. Robust regression downweights observations with larger absolute residuals using iterative weighted least squares (Andersen, 2008). 


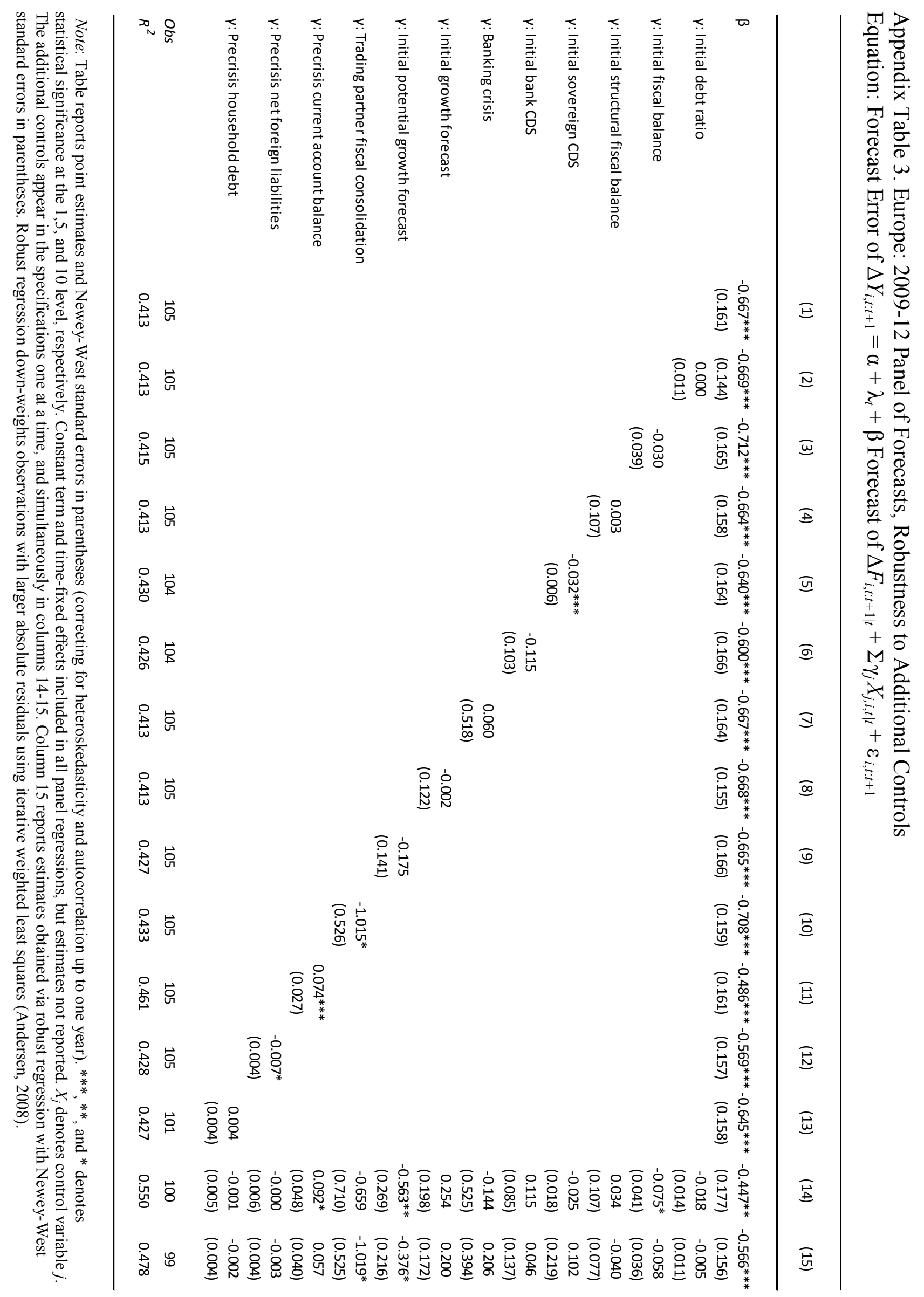




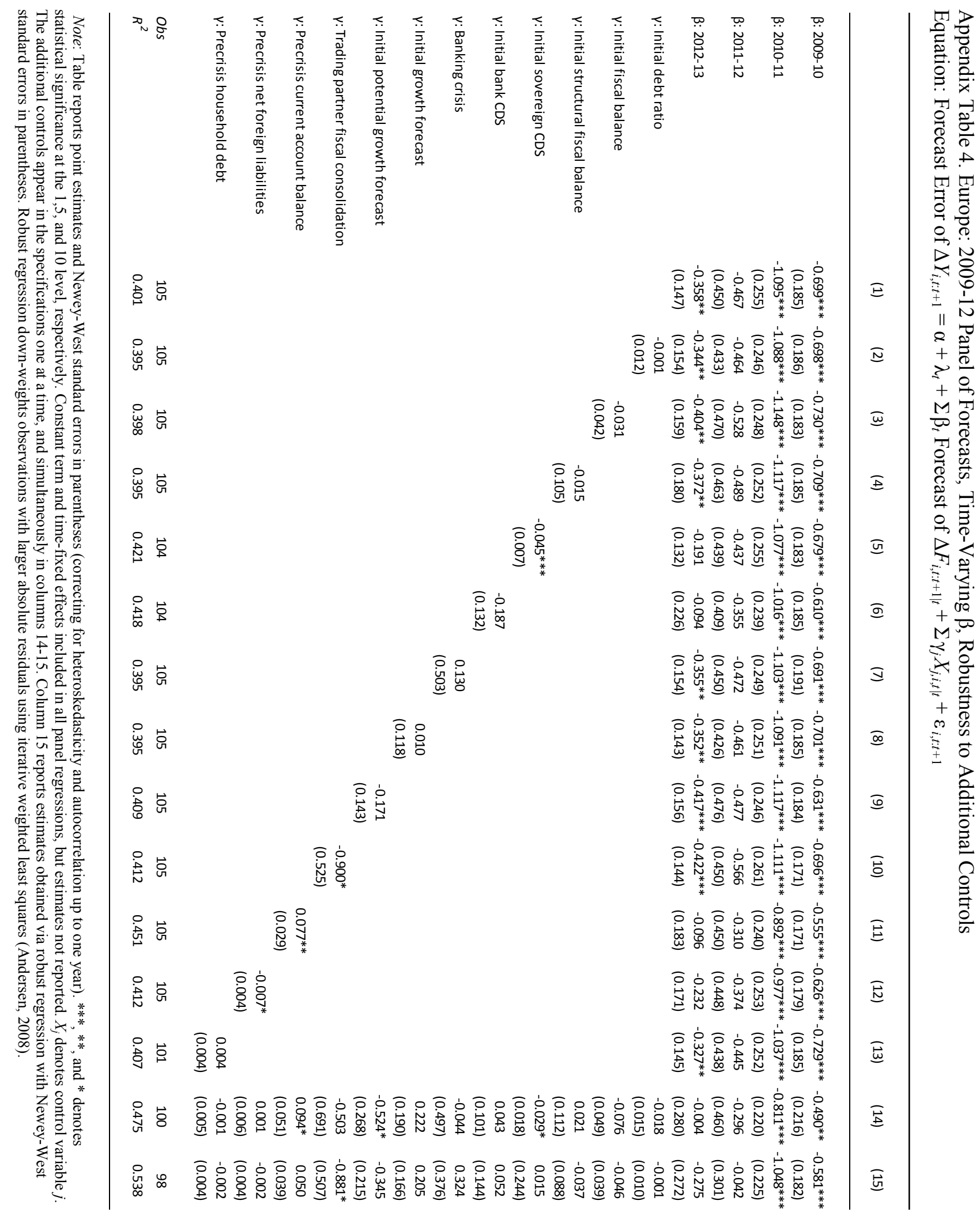


Appendix Table 5. Europe: 2009-12 Panel of Forecasts, Robustness to Additional Controls, Time-Varying $\beta$ and $\gamma$ Equation: Forecast Error of $\Delta Y_{i, t, t+1}=\alpha+\lambda_{t}+\Sigma \beta_{t}$ Forecast of $\Delta F_{i, t: t+1 \mid t}+\Sigma \gamma_{t} X_{i, t \mid t}+\varepsilon_{i, t: t+1}$

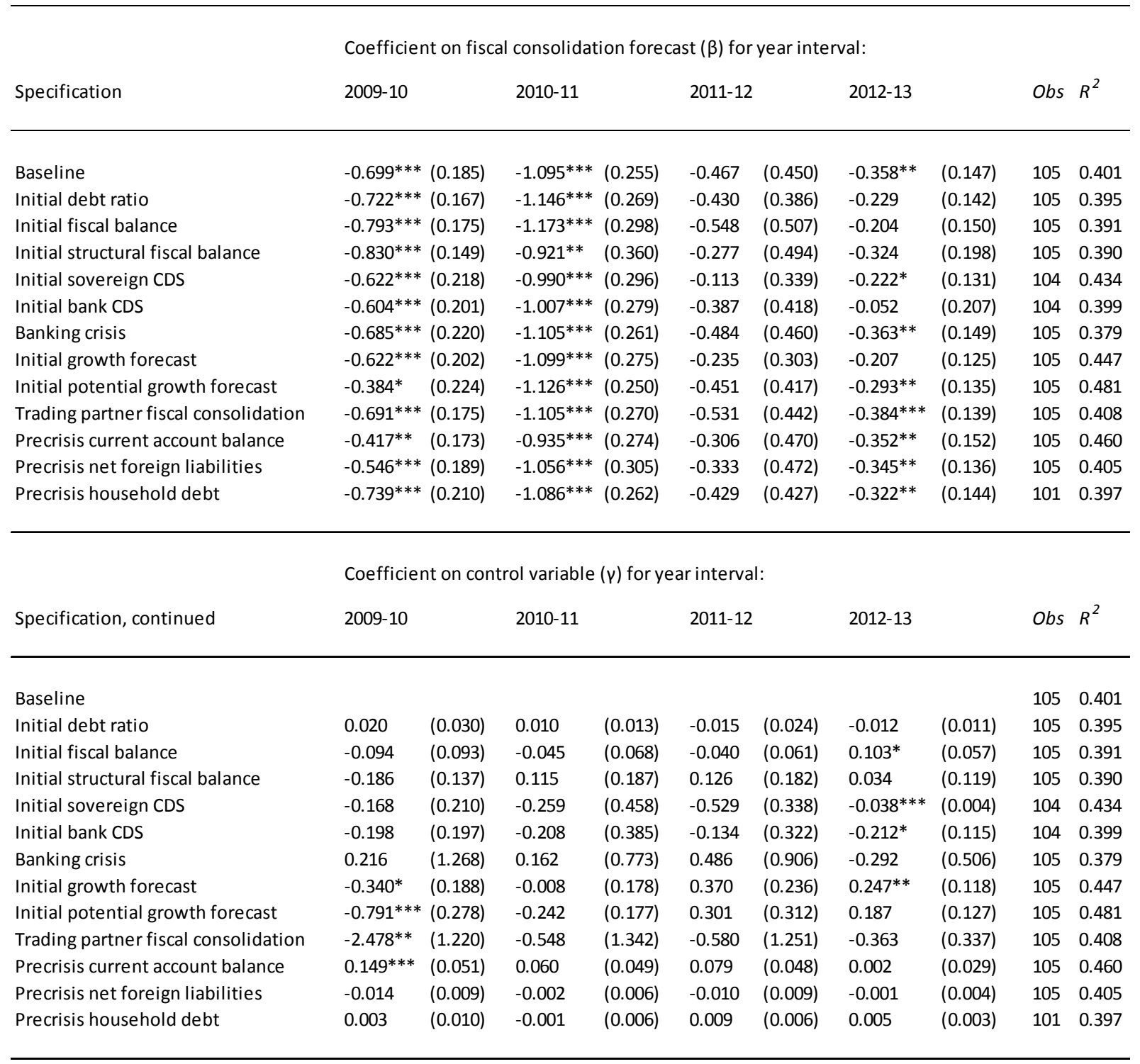

Note: Table reports point estimates and Newey-West standard errors in parentheses (correcting for heteroskedasticity and autocorrelation up to one year). $* * * * *$, and $*$ denotes statistical significance at the 1,5 , and 10 level, respectively. Constant term and time-fixed effects included in all regressions, but estimates not reported. Baseline specification with no control variables reported in first row. Coefficients on fiscal consolidation forecast $(\beta)$ and additional controls $(\gamma)$ allowed to vary over time. 
Appendix Table 6. Europe: 2009-12 Panel of Forecasts, Controlling for Vulnerability Rating

Equation: Forecast Error of $\Delta Y_{i, t: t+1}=\alpha+\lambda_{t}+\Sigma \beta_{t}$ Forecast of $\Delta F_{i, t: t+1 \mid t}+\Sigma \gamma_{t} V_{i, t \mid t}+\varepsilon_{i, t: t+1}$

(1)

(2)

(3)

(4)

$\beta$

$-0.667^{* * *}-0.724^{* * *}$

$(0.161) \quad(0.232)$

$-0.149$

$\beta: 2009-10$

(0.390)

$-0.699 * * * \quad-1.483^{*}$

(0.185) (0.822)

B: 2010-11

$-1.095 * * * \quad-0.718 * *$

(0.255) (0.329)

ß: 2011-12

$-0.467-0.833^{*}$

(0.450) (0.495)

B: 2012-13

$-0.358^{* *} \quad-0.227$

(0.147) (0.223)

ү:Vulnerability rating | 2009

$-0.825$

(1.725)

v: Vulnerability rating $\mid 2010$

$-1.039$

(0.707)

ү:Vulnerability rating | 2011

0.182

(0.835)

ү: Vulnerability rating | 2012

$-0.399$

(0.492)

\begin{tabular}{lcccc} 
Obs & 105 & 80 & 105 & 80 \\
$R^{2}$ & 0.413 & 0.509 & 0.401 & 0.489 \\
\hline
\end{tabular}

Note: Table reports point estimates and Newey-West standard errors in parentheses (correcting for heteroskedasticity and autocorrelation up to one year). ***,**, and * denotes statistical significance at the 1,5, and 10 level, respectively. Constant term and time-fixed effects included in all panel regressions, but estimates not reported. Coefficients on fiscal consolidation forecast $(\beta)$ and vulnerability rating $(\gamma)$ constant in columns 12 , and allowed to vary over time in columns 3-4. For methodology underlying vulnerability rating $(V)$, see IMF (2010c). 
Figure 1. Europe: Growth Forecast Errors vs. Fiscal Consolidation Forecasts

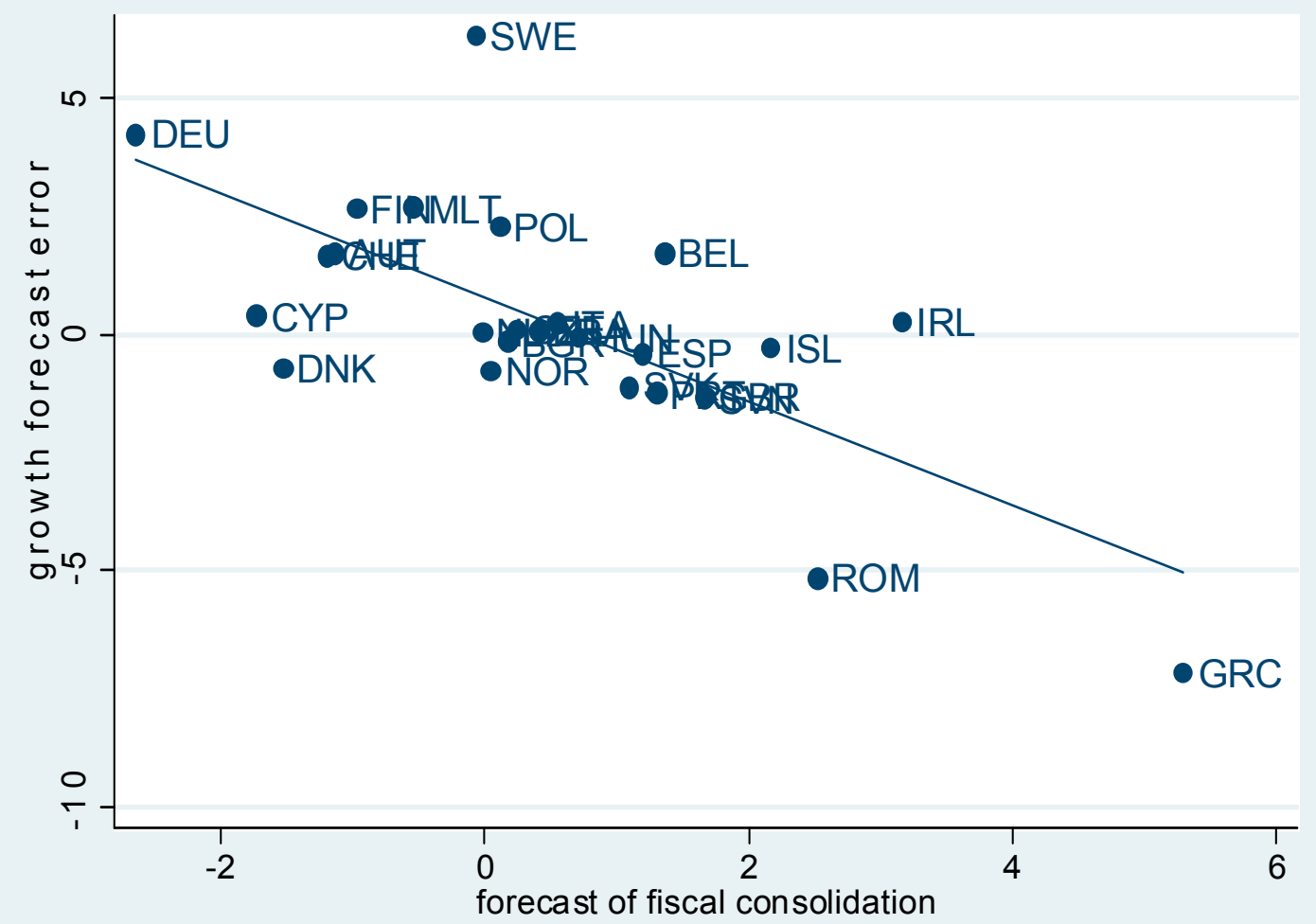

Note: Figure plots forecast error for real GDP growth in 2010 and 2011 relative to forecasts made in the spring of 2010 on forecasts of fiscal consolidation for 2010 and 2011 made in spring of year 2010; and regression line. 
Figure 2. Europe: 2009-12 Panel

Growth Forecast Errors vs. Fiscal Consolidation Forecasts

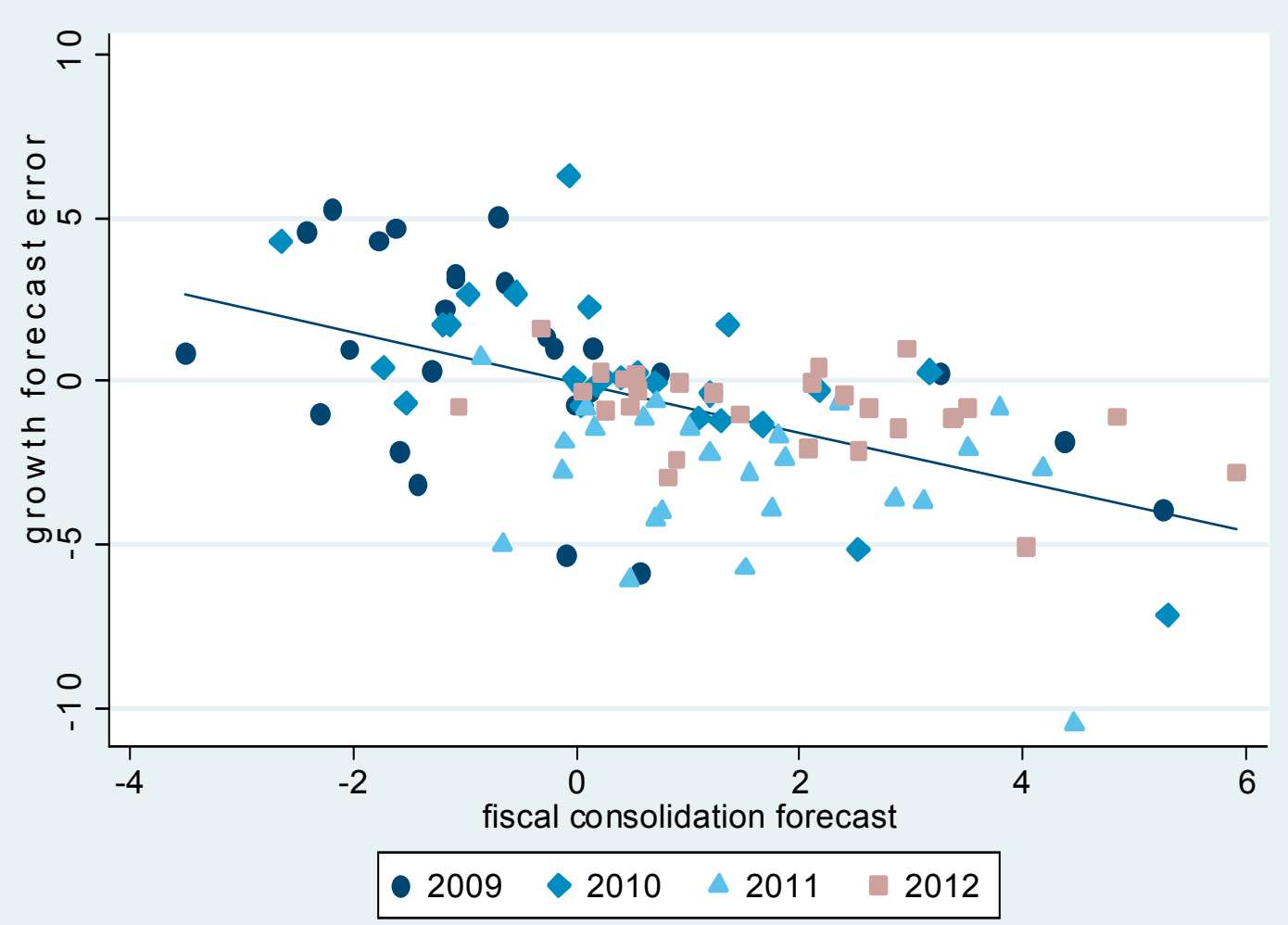

Note: Figure plots forecast error for real GDP growth in years $t$ and $t+1$ relative to forecasts made in the spring of year $t$ on forecasts of fiscal consolidation for $t$ and $t+1$ made in spring of year $t$, for years $t=2009,2010$, 2011, and 2012; and simple regression line for panel of observations without time effects. 
Figure 3. All Advanced Economies: 2009-12 Panel

Growth Forecast Errors vs. Fiscal Consolidation Forecasts

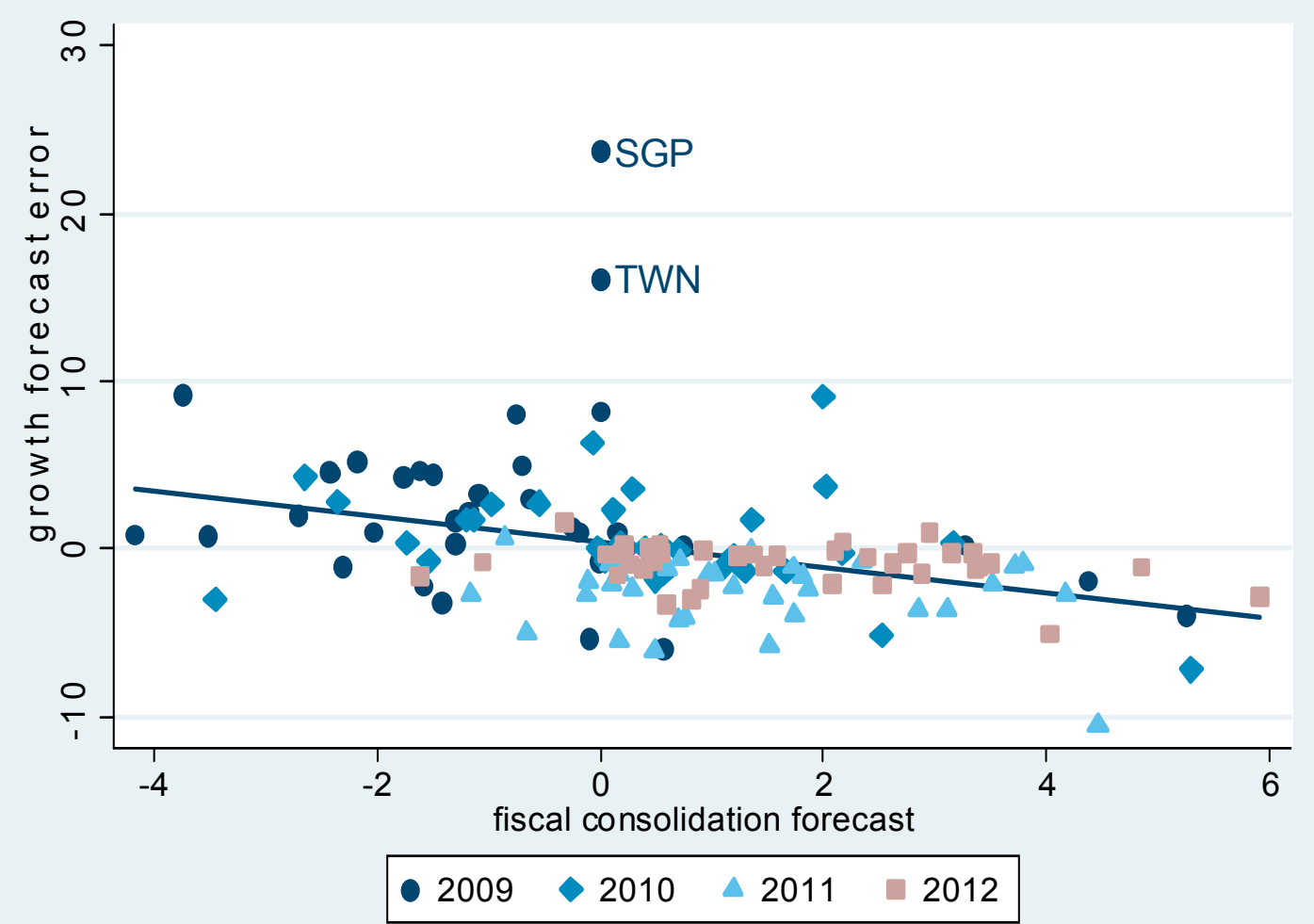

Note: Figure plots forecast error for real GDP growth in years $t$ and $t+1$ relative to forecasts made in the spring of year $t$ on forecasts of fiscal consolidation for $t$ and $t+1$ made in spring of year $t$, for years $t=2009,2010$, 2011, and 2012; and simple regression line for panel of observations without time effects. 